\title{
LAS INSCRIPCIONES CONSTRUCTIVAS DE LA ÉPOCA DEL GOBIERNO DE ALMANZOR *
}

\author{
JUAN A. SOUTO \\ Universidad Complutense de Madrid
}

Se presentan y comentan los datos de las inscripciones constructivas andalusíes correspondientes al período de gobierno de Almanzor (976-1002).

Palabras clave: al-Andalus; inscripciones; construcción; Almanzor.
Data on Andalusi construction inscriptions from the period of al-Manșūr (976-1002) are presented and discussed.

Keywords: Al-Andalus; Inscriptions; Building; Al-Manșūr b. Abī' 'Āmir.

\section{Introducción}

Las inscripciones constructivas ocupan un lugar destacado entre las fuentes históricas de la etapa de gobierno de Almanzor (9761002) ${ }^{1}$, pues además de ser documentos originales que hablan (no

*Este trabajo se inscribe en el proyecto de investigación "Epigrafía y construcción en al-Andalus omeya", subvencionado por la Fondation Max van Berchem y cuyos planteamientos básicos figuran en Souto, J. A., "Epigraphy and building in Umayyad al-Andalus: genesis and prospects for a research project", en Vermeulen, U., y De Smet, D. (eds.), Philosophy and Arts in the Islamic World. Proceedings of the Eighteenth Congress of the UEAI, Orientalia Lovaniensia Analecta, 87, Lovaina, 1998, 303-24. La Fundación Max van Berchem fue constituida en 1973 en homenaje a Max van Berchem (1863-1921), fundador de la epigrafía árabe como disciplina. Establecida en Ginebra, tiene como meta el promover el estudio de la arqueología, la historia, la geografía, la historia del arte, la epigrafía, la religión y la literatura árabes e islámicas. El autor desea agradecer a los Dres. Camilo Álvarez de Morales y Christian Ewert el facilitarle bibliografía inaccesible en Madrid y documentos personales que le han sido de gran utilidad; y a Carmen Carriazo, sus numerosas ideas y sugerencias. Una primera versión de lo que aquí se publica fue presentada como comunicación en la sección "Fuentes textuales de al-Andalus en los siglos X y XI" del Congreso Internacional Almanzor y su época, celebrado en Córdoba en noviembre de 2002.

${ }^{1}$ La bibliografía sobre este período es muy amplia. A los pasajes de la clásica obra de Lévi-Provençal, volumen IV de la Historia de España de Menéndez Pidal (Madrid, 1957, con numerosas reediciones posteriores), pueden añadirse, sin ánimo de exhaustividad, los contenidos en Vallvé, J., El califato de Córdoba, Madrid, 1992; Valdés Fernández, F. (coord.), La Península Ibérica y el Mediterráneo entre los siglos XI y XII-II. 
siempre con palabras) de los objetos que los soportan, de sus mecenas, sus hacedores y el papel de unos y otros en la sociedad del momento, las inscripciones constructivas fueron concebidas para ser $e x-$ puestas - aunque algunas no tanto, como se verá-, son parte esencial del programa visual de sus obras arquitectónicas, con todas las implicaciones que esto trae consigo ${ }^{2}$. En este sentido, la colección que ha llegado a nuestros días es muy afortunada por la variedad de obras documentadas, soportes, mecenazgo, funciones... Sin olvidar los problemas metodológicos que plantea su estudio y que tantas horas de placer me han proporcionado por el momento.

Hablaré aquí de las inscripciones a renglón seguido y presentaré su documentación en forma de fichas e ilustraciones, conformando así el catálogo hoy por hoy completo, que yo sepa, de una colección diplomática tan fascinante como dispersa y con elementos a mi juicio poco atendidos por la investigación ${ }^{3}$. El orden de exposición y pre-

Almanzor y los terrores del milenio, Aguilar de Campoo, 1999; Martínez Enamorado, V., y Torremocha Silva, A., Almanzor y su época. Al-Andalus en la segunda mitad del siglo X, Málaga, 2001; ídem (eds.), Al-Andalus y el Mediterráneo en torno al año 1000. La época de Almanzor, Algeciras, 2003; Bariani, L., Almanzor, San Sebastián, 2003; Ballestín Navarro, X., Al-Mansur y la dawla 'amiriya. Una dinámica de poder y legitimidad en el occidente musulmán medieval, Barcelona, 2004; Casa, C. de la y Martínez, Y. (dirs.), Cuando las horas primeras. En el Milenario de la Batalla de Calatañazor, Soria, 2004 y Manzano Moreno, E., Conquistadores, emires y califas, Barcelona, 2006. En todas estas obras se recoge bibliografía anterior.

2 Souto, J. A., "Epigraphy and building", pas., y Souto, J. A., "Las inscripciones árabes de la iglesia de Santa Cruz de Écija (Sevilla): dos documentos emblemáticos del Estado omeya andalusí”, Al-Andalus-Magreb, 10 (2002-2003) 215-63, pas. No incluyo en esta categoría de inscripciones constructivas los "complementos arquitectónicos" epigrafiados, tales como la pila del Museo Arqueológico Nacional o el almimbar hoy en la Mezquita de los Andalusíes de Fez, ya que no hacen referencia directa a ningún edificio, por más que "su naturaleza implique la construcción de grandes monumentos", en palabras de Blair, S. S., The Monumental inscriptions from early Islamic Transoxiana and Iran, Leiden, 1992, 4. Y en cuanto a los objetos epigrafiados suntuosos y de uso "personal", como los marfiles, constituyen su auténtico contrapunto, pues aunque sus inscripciones también hablan de ellos, sus hacedores y sus mecenas o propietarios, es evidente que no es lo mismo ni tiene las mismas intenciones lo que se muestra al público y permanentemente - epígrafe expuesto - que lo que se muestra en privado, a un círculo restringido o en circunstancias excepcionales. Últimas consideraciones generales sobre "complementos arquitectónicos" y objetos suntuosos en este período: Almanzor y su época, 184-89.

${ }^{3}$ La bibliografía citada en las fichas comprende sólo ediciones y traducciones únicas o que difieren de otras anteriores. En las notas al texto se encontrará orientación bibliográfica más amplia.

Al-Qanțara (AQ) XXVIII 1, enero-junio 2007, pp. 101-142 ISSN 0211-3589 
sentación es el cronológico, ya que es en el que fueron hechas tanto las inscripciones como las obras que documentan ${ }^{4}$.

\section{Las inscripciones y las obras que documentan}

\subsection{Azacaya de Écija (Inscripción n. ${ }^{0}$ 1-Lámina I y figura 1) ${ }^{5}$}

En el mes de muharram de 318/3 febrero-2 marzo 930 'Abd al-Raḥmān III ordenó la [re]construcción (bunyān) ${ }^{6}$ de una azacaya en Écija (Sevilla). En el mes de $r a b i^{-}$II de 367/16 noviembre-14 diciembre 977 hizo otro tanto Șubh, la madre de su nieto, el ya entonces califa Hišām II. Esta inscripción conmemora la segunda iniciativa.

Constituye un modelo completo y representativo de lo que debía ser una inscripción constructiva andalusí oficial de la época, tanto desde el punto de vista de sus caracteres externos (soporte y tipo de escritura) como de los internos (el texto en sí): el soporte es una lápida de mármol; la escritura es del tipo «cúfico florido» ${ }^{7}$; y, en cuanto al texto, reproduce un esquema general bien conocido ${ }^{8}$.

${ }^{4}$ Las inscripciones atribuibles a períodos más o menos amplios están ordenadas de menor a mayor amplitud y correlativamente. No incluyo inscripciones no fechables, de cronología más que dudosa o cuyo margen cronológico posible supera, por arriba o por abajo, los límites de 976 y 1002.

${ }^{5}$ Los datos y comentarios que siguen resumen contenidos de "Las inscripciones de Écija", n. ${ }^{\circ}$ 2. Últimas consideraciones en Barceló, C., "El cúfico andalusí 'de provincias' durante el califato (300-403/912-1013)”, Cuadernos de Madinat al-Zahrā', 5 (2004), $173-97,{ }^{\circ}{ }^{\circ} 42$ y figura 3 .

6 Nombre de acción del verbo banà, dotado del ambiguo significado de "construir" y "reconstruir", que podría resumirse en "hacer obras" y que desde hace ya tiempo traduzco por "[re]construir" (Souto, J. A., "Textos árabes relativos a la Mezquita Aljama de Zaragoza", Madrider Mitteilungen, 30 (1989), 391-426, pas.).

7 Sólo hay una letra con remate floral, pero considero que es suficiente para considerar el conjunto como "cúfico florido" y no como "cúfico simple", nombre hasta hace poco asociado por sistema a la cronología más que a la morfología. En esto me muestro de acuerdo con Martínez Enamorado, V., Un hombre para el califato. De nuevo sobre $\hat{Y} a$ 'far el Eslavo a partir de un cimacio con grifos, Málaga, 2006, 15. Sobre el "cúfico florido" en al-Andalus, véase Ocaña Jiménez, M., El cúfico hispano y su evolución, Madrid, 1970, 26-35; Fernández-Puertas, A., "Calligraphy in al-Andalus", en Jayyusi, S. K. (ed.), The Legacy of Muslim Spain, Leiden, 1994, 642-43; y Martínez Núñez, M. a A., "Escritura árabe ornamental y epigrafía andalusí", Arqueología y territorio medieval, 4 (1997), 132-34.

8 Esquema algo variable por diversos factores y a lo largo del tiempo: cf. Rodríguez, M. a J., y Souto, J. A., "De Almanzor a Felipe II: la inscripción del Puente de Alcántara de 
Lo más llamativo de este epígrafe es que en él no figura el nombre propio del sujeto de la orden, Subh, sino que su identidad se expresa a través de sus títulos, de «una eulogia propia hasta entonces de soberanos (a'azza-hā Allāh) y una kunya muy larga y reveladora - título, laqab y filiación de Hišām, seguida de una expresión también exclusiva del califa - todo para exhibirse diáfanamente sin tener que plasmar su onomástico y para dejar bien patente la verdadera identidad del legítimo monarca de al-Andalus, en cuyo nombre ella gobernaba y cuya legitimidad preservaba. La personalidad de la madre queda lo suficientemente clara como para que nadie dude de ella. La publicación de su nombre, ¿se obviaría por innecesaria, porque hubiera sido un exceso de atrevimiento o por ambas cosas?» ${ }^{9}$. Y eso que no falta la consabida alusión al director honorífico de la obra, el cadí de las gentes de Écija y Carmona y sus distritos, que además era jefe de policía y sanī $a$ —que podría traducirse por «protegido» o «paniaguado»— de la señora en cuestión ${ }^{10}$. No cabe duda de que ésta era, junto con (o puede que entonces todavía por encima de) el propio Almanzor, la auténtica «soberana» de al-Andalus.

Quien se revela como un personaje casi patético es Hišām II, teóricamente jefe del Estado pero, en realidad, relegado a justificación legal de su verdadera rectora. Volveré sobre ello.

\subsection{Signos lapidarios epigráficos en la Mezquita Aljama de Córdoba (Inscripción n. ${ }^{\circ}$ 2-Figura 2)}

Uno de los pilares del poder de Almanzor fue su política de $\hat{y} i h \bar{a} d$ o esfuerzo por la salvaguarda y expansión del Islam. La más contundente

Toledo (387/997-998) y su curiosa historia”, Al-Qanțara, XXI (2000), 192 y nota 17 para bibliografía suplementaria; y Martínez Núñez, M. a A., "Sentido de la epigrafía omeya de

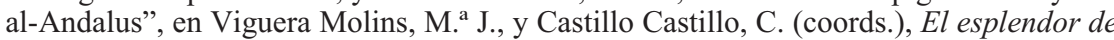
los Omeyas cordobeses. La civilización musulmana de Europa Occidental. Estudios, Granada, 2001, 408-17, pas.

9 "Las inscripciones de Écija", 258.

10 Sobre la cuestión de la dirección honorífica o real de las obras en al-Andalus omeya, véase Ocaña Jiménez, M., "Arquitectos y mano de obra en la construcción de la gran mezquita de Occidente", Cuadernos de la Alhambra, 22 (1986), 55-85; Souto, J. A., "La práctica y la profesión del artista en el Islam: arquitectos y constructores en al-Andalus omeya", Espacio, Tiempo y Forma, Serie VII, 10 (1997), 11-34; ídem, "Los constructores de al-Andalus Omeya", en Viguera Molins, M. ${ }^{a}$ J., y Castillo Castillo, C., (coords.), El esplendor de los omeyas cordobeses, 274-81.

Al-Qanțara (AQ) XXVIII 1, enero-junio 2007, pp. 101-142 ISSN 0211-3589 
expresión visual de esto fue, sin duda, la ampliación que hizo de la Mezquita Aljama de Córdoba ${ }^{11}$. Su cronología no está del todo clara, pues si bien el cronista Ibn 'Id̄ārī apunta el año 377/987 como el de inicio de las obras, el anónimo Dikr bilād al-Andalus señala que éste tuvo lugar en 381/991, que la primera oración se hizo allí en 384/994 y que el conjunto de las intervenciones se terminó en 390/999-1000. Es evidente que la segunda fuente resulta más fiable por aportar más detalles cronológicos; por otra parte, su lectura permite colegir que en 994 estaba terminado el oratorio, que es lo que aquí interesa ${ }^{12}$.

Esta imprecisión cronológica está reforzada por la ausencia de inscripción alguna con fecha explícita, pues Almanzor no quiso dejar ningún epígrafe conmemorativo de su intervención, no permitió que en la Aljama figurase su nombre escrito en piedra. Era muy consciente de la importancia de semejante documento y del insulto que supondría contra la legitimidad omeya que pretendía defender y de la que su obra era una clara propaganda. Sin embargo, tampoco hay en el edificio ninguna inscripción constructiva a nombre del califa, Hišām II ${ }^{13}$. Todo es significativo.

Frente a ello, la Mezquita Aljama de Córdoba constituye un verdadero museo gliptográfico: en ella se conservan más de setecientos signos lapidarios tallados en puntos no siempre bien visibles de elementos de columnas de las fases constructivas de al-Hakam II y Almanzor, casi todos en el oratorio, aunque hay unos cuantos en el patio de la Catedral y en una casa frontera de ella ${ }^{14}$.

${ }^{11}$ Una magnífica síntesis acerca de este monumento se encuentra en Ewert, C. y Wisshak, J. P., Forschungen zur almohadischen Moschee. Lieferung 1: Vorstufen, Maguncia, 1981, pas., de donde procede la nomenclatura de las columnas empleada en la figura 2 de este trabajo; la más reciente y actualizada, con bibliografía exhaustiva, está en la primera parte de Nieto Cumplido, M., La Catedral de Córdoba, Córdoba, 1998; véase también Marfil Ruiz, P., "Ampliación de la mezquita de Córdoba por Almanzor", en La época de Almanzor, 77-85.

12 Consideración comparada de datos en Nieto Cumplido, M., La Catedral de Córdoba, 281-83.

${ }^{13}$ Lo que destaca Torres Balbás, L., "Arte hispanomusulmán hasta la caída del califato de Córdoba", en Historia de España dirigida por Ramón Menéndez Pidal, V, reed., Madrid, 1982, 573, con referencias a fuentes concretas.

${ }^{14}$ Cabe preguntarse cuántos habrá que no se ven por haber sido tallados en caras hoy ocultas de las piezas. Sobre los signos lapidarios y la gliptografía (ciencia que los estudia), véanse las actas de los Coloquios Internacionales de Gliptografía celebrados hasta ahora, publicadas casi todas ellas en Braine-le-Château (Bélgica) entre 1979 y 2005. Sobre los signos de la Mezquita Aljama de Córdoba, véase la bibliografía de la ficha y mis siguientes publicaciones: "Glyptographie omeyyade: signes lapidaires à la Grande Mos- 
De estos signos interesan aquí los epigráficos de la última fase ${ }^{15}$, que pueden dividirse en árabes, latinos y pseudoepigráficos. Los árabes son onomásticos aislados - algunos de ellos escritos a la inversa, como vistos «en espejo»-, onomásticos dobles unidos mediante conjunción y sintagmas de rección compuestos por la palabra 'amal («obra») como regente de un nombre propio que le sigue. En cuanto a los latinos, consisten en letras aisladas o formando conjuntos de dos, tres y cuatro, a veces entre dos líneas. Los pseudoepigráficos podrían ser intentos fallidos de plasmar correctamente grafemas árabes de nombres propios.

Por el tipo de escritura, los signos epigráficos árabes corresponden tanto al llamado «cúfico», con elaboración más o menos cuidada según el caso, como al llamado «cursivo», que llega a salpicarse de puntos diacríticos. Las letras latinas son siempre capitales sentadas. En cuanto a la técnica de talla, frente a las cuidadas inscripciones «oficiales», la de estos signos es mayoritariamente incisa por piqueteado con puntero ${ }^{16}$, aunque hay unos cuantos casos de epigráficos árabes cuidadosamente tallados en resalto.

quée de Cordoue. Documentation de noms propres", Actes du XII Colloque International de Glyptographie de Saint-Christophe-en-Brionnais, Braine-le-Château, 2001, 283-307; "La construcción en al-Andalus omeya: las marcas de identidad de tallistas de piedra", en Pino García, J. L. del (coord.), Al-Andalus omeya, Córdoba, 2002, 105-18; "Stonemasons" identification marks as a prosopographical source: the case of Umayyad al-Andalus", en Marín, M. (ed. y coord.), Arab-Islamic Medieval Culture, monográfico de Medieval Prosopography, 23 (2002), 229-45; "Glyptographie omeyyade: croquis de travailleurs de la Grande Mosquée de Cordoue", Actes du XIII ${ }^{e}$ Colloque International de Glyptographie de Venise, Braine-le-Château, 2003, 361-84; "Glyptographie omeyyade: croquis de travailleurs de la Grande Mosquée de Cordoue. Nouvelles découvertes", Actes du XIVe Colloque International de Glyptographie de Chambord, Braine-le-Château, 2005, 423-43; y "De gliptografía omeya: el nombre de Fath en la Mezquita Aljama de Córdoba", en Aguadé, J., Vicente, Á. y Abu Shams, L. (eds.), Sacrum arabo-semiticum. Homenaje al profesor Federico Corriente en su 65 aniversario, Zaragoza, 2005, 453-77. A ellas hay que añadir la de Rodríguez Pérez, R., "Numismática y gliptografía. Notas acerca de unas marcas de identidad de la Mezquita Aljama de Córdoba y sus antecedentes en feluses de al-Andalus", Actes du XVe Colloque Internacional de Glyptographie de Cordoue, en prensa. Los párrafos que siguen contienen datos e ideas expresados en ellas.

15 Trato aquí este amplio conjunto como "una sola inscripción", tan sólo por razones prácticas.

${ }^{16}$ El puntero es un tipo de cincel de extremo agudo: Manzella, I. di S., Mestiere di epigrafista. Guida alla schedatura del materiale epigrafico lapideo, Roma, 1987, 55 y fig. 13, n. ${ }^{\circ} 15$; Bessac, J. C., L'Outillage traditionnel du tailleur de pierre de l'Antiquité à nos jours, París, 1993, n. ${ }^{\circ}$ 9; y Teixidó i Camí, J. y Chicharro Santamera, J., Escultura en piedra, Barcelona, 2003, 54.

Al-Qanțara (AQ) XXVIII 1, enero-junio 2007, pp. 101-142 ISSN 0211-3589 
Parece claro, dado lo dicho, que nos encontramos ante inscripciones cuya finalidad no era la contemplación por parte del público. ¿Cuál era, entonces? Considero que se trata de «documentos de orden interno» para uso de los propios constructores, concretamente marcas de identidad de tallistas, es decir, signos relativos a la identidad de los autores de la talla de piezas concretas. Prueba de ello son su carácter «escueto» tanto en contenido como en forma, sus soportes, exclusivamente elementos de columnas - lo que remite a especialistas-, y su situación en general «discreta». Son, pues, testimonio de «los más bajos estamentos de la construcción», últimos eslabones de una cadena que tiene como cúspide al auténtico soberano en persona, en este caso el usurpador Almanzor.

Varios de los nombres propios presentes en forma de signos lapidarios en la Mezquita Aljama de Córdoba aparecen documentados epigráficamente fuera de ella y en época coetánea, lo que plantea interesantes cuestiones relativas a la identidad de los autores y a sus cometidos.

\subsection{Capitel en la fachada oriental de la Mezquita Aljama de Córdoba (Inscripción n. ${ }^{\circ}$ 3-Lámina II)}

Se trata de un capitel de orden compuesto, con decoración vegetal, contario y una cartela en la que un escueto sintagma de rección, escrito en buen cúfico de resalto, permite conocer el nombre de su autor: Ibn Badr, «Hijo de Badr». La cronología de la pieza sería contemporánea de la de las obras en que se inserta, es decir, entre 987 y $1000{ }^{17}$.

Nos apartamos aquí de los austeros signos lapidarios tallados sobre los igualmente austeros capiteles del interior del oratorio para encontrarnos ante una obra de exhibición exterior donde la inscripción, si bien de texto muy breve, tiende a ser tan preciosista como su soporte.

¿Sería este Ibn Badr hijo del Badr (o de uno de los Badr) que estampó su firma en Madīnat al-Zahrā' y en piezas de columnas de la ampliación de al-Ḥakam II en la Aljama de Córdoba? ${ }^{18}$

17 "Si admitimos que está in situ, o que por lo menos se hizo para esta fachada, habría que fecharlo hacia el 990 d.C." (Brisch, K., "Sobre un grupo de capiteles y basas islámicas del siglo XI de Toledo", Cuadernos de la Alhambra, 15-17 (1979-81), 162). Sobre la cronología de esta ampliación del edificio, véase el apartado anterior.

${ }^{18}$ Souto, J. A., "Documentation de noms propres", n. ${ }^{\circ} 2.2$. 


\subsection{Puente de Alcántara de Toledo (Inscripción n. ${ }^{\circ}$ 4-Lámina III y figura 3) ${ }^{19}$}

El Puente de Alcántara, principal de la ciudad de Toledo, fue objeto de numerosas obras constructivas a lo largo de su historia. Algunas de ellas fueron documentadas mediante inscripciones que, por desgracia, no siempre se han conservado, al menos las originales. Tal es este caso, interesantísimo desde el punto de vista metodológico: la inscripción conmemorativa de las obras ordenadas por Almanzor, fechada en 387/4 enero 997-2 enero 998, se perdió en un momento determinado —no sabemos cuándo- - pero se conserva un resumen-traducción de ella al castellano, hecho en 1259 y contenido en una inscripción del rey Alfonso X «el Sabio», a su vez «reparada» en 1575 por orden de Felipe II y bajo la supervisión del corregidor Juan Gutiérrez Tello. Del análisis de ese resumen-traducción puede reconstruirse la inscripción árabe tal y como la presento.

\footnotetext{
Ignoramos a qué parte o partes del Puente de Alcántara se refería (...). Es evidente que no constituye un documento de carácter fundacional, puesto que el edificio en cuestión ya existía para la fecha, sino que conmemoraba obras de reconstrucción, reparación, ampliación o acondicionamiento más o menos importantes. Junto con este objetivo inmediato hay otro no menos esencial, la doble exaltación de Almanzor como benefactor de la comunidad al mandar hacer obras en un puente y como fiel servidor del califa. La constancia por escrito del nombre y el cargo del gobernador también forma parte integrante de este programa propagandístico, no el último, que tenía como soporte este puente concreto ${ }^{20}$.
}

Otros rasgos destacables de esta inscripción son el hecho de que en ella Almanzor consta con el título de wazir y que el tal gobernador $(q \bar{a}$ ’id) de Toledo, bajo cuya dirección se hicieron la obras, era un personaje llamado Jalaf $b$. Muhammad al-'Āmirī, del que cabe preguntarse si tendría algo que ver con el Jalaf al-'Āmirī que hay entre los firmantes de piezas de columnas en la última ampliación de la Mezquita Aljama de Córdoba (figura 2: f).

${ }^{19}$ Los datos y comentarios proceden de "De Almanzor a Felipe II". Últimas consideraciones en "El cúfico andalusí 'de provincias", n. ${ }^{\circ} 51$.

${ }^{20}$ Souto, J. A., "De Almanzor a Felipe II", 199-200.

Al-Qanțara (AQ) XXVIII 1, enero-junio 2007, pp. 101-142 ISSN 0211-3589 


\subsection{Mezquita de «Las Paredes», Logrosán, Cáceres (Inscripción n. ${ }^{\circ}$ 5-Lámina IV y figura 4) ${ }^{21}$}

Se trata del documento epigráfico de una iniciativa constructiva - concretamente, una reforma o reparación ${ }^{22}$ - por parte de un mecenas particular, rural y pobre, lo que se deduce de sus caracteres externos e internos, pues la inscripción en cuestión contrasta en varios aspectos con los epígrafes oficiales andalusíes de la época.

En primer lugar por su soporte, que en vez de ser una lápida de mármol bien tallada, como las inscripciones 1, 4 (muy posiblemente) y 11, es una laja de pizarra, material tosco y asequible a pie de obra, por lo tanto barato; en segundo por la escritura, que no es de tipo cúfico, sino de uno cursivo - poco cuidado, por cierto- en que el escriba no se ha privado de introducir puntos diacríticos allí donde podrían surgir problemas de interpretación. Tampoco su técnica de inscripción es difícil ni cara, pues la escritura es incisa y no excisa ${ }^{23}$; y en tercero, por sus caracteres internos, ya que faltan la basmala, la orden de construcción, el nombre del ordenante, fórmulas propiciatorias, alusiones al auxilio divino, al director (honorífico o real) del trabajo... ${ }^{24}$. Por otra parte, y pese a lo difícilmente legible - y por tanto hipotético- de las primeras palabras conservadas, la expresión min amwāli-hi («con sus riquezas») indicaría la fuente de financiación de las obras, el propio bolsillo de ese particular; li-dawi l-maydān, «para las gentes de la explanada», aludiría a quién iban dirigidas, sus

${ }^{21}$ Los datos y buena parte de los comentarios que siguen proceden de Gilotte, S., González, A., y Souto, J. A., "L'Inscription d'époque omeyyade de la mosquée de 'Las Paredes' (Logrosán, Cáceres, Espagne) ”, Archéologie Islamique, 10 (2000), 55-64.

${ }^{22}$ El verbo con que se expresa es așlaha ("reformar", "reparar"), empleado aquí por primera vez con sentido constructivo en la epigrafía andalusí.

23 "Una cantera próxima y asequible, capaz de hacer ahorrar mucho o todo el coste del transporte, una piedra blanda, adecuada para recibir la escritura común sin el gasto del taller o una piedra de desecho, asignan el monumento acabado al pobre o al proletario. Así, las capas sociales de renta baja, los protagonistas de las culturas plebeyas y subalternos son conocidos proporcionalmente al grado de facilidad de acceso a la cantera y al grado de maleabilidad de la piedra barata", según palabras de G. Susini, apud Manacorda, D., "Epigrafía, arqueología", en Francovich, R., y Manacorda, D. (eds.), Diccionario de arqueología, Barcelona, 2000, que aunque relativas a la Antigüedad clásica, son perfectamente aplicables a este caso. El subrayado es mío.

${ }^{24}$ En este último aspecto hay que ser cautos, sin embargo, pues no puede descartarse que la pieza, reutilizada como gorronera o quicialera, esté incompleta. Sobre las fórmulas de las inscripciones constructivas omeyas andalusíes oficiales, véase la bibliografía citada en la nota 8 . 
paisanos ${ }^{25}$; el verbo takassaba-hā («la adquirió») presenta un problema, su pronombre sufijado, que no sé a qué se refiere (recuérdese que «mezquita» en árabe es masculino).

Desgraciadamente, nada se ha conservado del edificio documentado por esta inscripción, y el yacimiento del que procede es muy pobre y poco elocuente en cuanto a datos de superficie.

\subsection{Mezquita de Bāb al-Mardūm, Toledo (Inscripción n. ${ }^{\circ}$ 6-Lámina $\mathrm{V}$ y figura 5) ${ }^{26}$}

De nuevo un texto conmemorativo de la construcción de una mezquita por un particular, de nombre Ahmad b. Hadīdī 27; pero las diferencias respecto del documento de «Las Paredes» son más que notables. En primer lugar está el soporte, todo un friso, parte del propio edificio y que da a la calle; en segundo, su material, ladrillos tallados, algo no especialmente caro pero tampoco barato; en tercero, el tipo de escritura, «cúfico simple», muy oficialista; y en cuarto, los caracteres internos, ya que el texto está formado por una sucesión de fórmulas bien establecidas y con paralelos en las inscripciones estatales.

Como el mecenas de «Las Paredes», y a diferencia de los rectores del Estado, Aḥmad b. Hadīdī, miembro de una notable familia toledana, no ordenó nada: antes bien, su testimonio escrito especifica que edificó una mezquita «de su peculio» ${ }^{28}$ para hacerse un sitio en el Paraíso, no sin dejar constancia en la Tierra de su obra en pro del Islam, con lo que ganaba prestigio de cara a sus conciudadanos, a quienes por lo demás no menciona ${ }^{29}$. La fórmula empleada para expresar «bajo la direc-

${ }^{25}$ Cabe entonces preguntarse si al-maydān sería un topónimo.

${ }^{26}$ Los datos y reflexiones que siguen proceden de Ewert, C., "La mezquita de Bāb al-Mardūm de Toledo (Cristo de la Luz): Una 'copia' de la mezquita de Córdoba", en Larriba, M. Á. (coord.), Entre el Califato y la Taifa: Mil años del Cristo de la Luz, Toledo, 2000, 11-52; King, G. R. D., "The Mosque of Bâb al-Mardûm and the Islamic building tradition", entre las pp. 269-86 del mismo volumen; y Souto, J. A., "Epigraphy and building", apartado n. ${ }^{\circ}$ 3. Véase también Barceló, C., "El cúfico andalusí 'de provincias"”, n. ${ }^{\circ} 54$.

27 En este caso se trata de la fundación ex novo, lo que se concluye del verbo empleado, aqūma, "erigir", "levantar", frente al așlaḥa del ejemplar anterior.

${ }_{28}$ Min māli-hi reza la inscripción, siendo $m a \bar{l}$ el singular de amwāl, vocablo empleado en la lápida anterior.

29 De ser correcta la lectura min-amwāli-hi li-dawī l-maydān de la inscripción anterior, nos encontraríamos ante un paralelo bastante claro, doblemente explícito en "Las

Al-Qanțara (AQ) XXVIII 1, enero-junio 2007, pp. 101-142 ISSN 0211-3589 
ción de», 'alà yaday, debe ser interpretada muy literalmente, ya que se refiere a Mūsà b. 'Alī, un bannā' («constructor», «arquitecto») ${ }^{30}$ que aparece en compañía de un posible ayudante llamado Sa'āda ${ }^{31}$.

Desde el punto de vista formal, el plutócrata local se «limitó»a construir una mezquita «de barrio», aunque su situación cerca de una de las puertas de la ciudad le daría cierta importancia y mucha visibilidad. Al hacerlo, imitó lo mejor que pudo las directrices materiales del sultán edificando una interesante copia del principal santuario estatal, la Aljama cordobesa. No aspiraba a más: su obra no es una exhibición de poder político, sino una muestra de sometimiento, implícito y explícito, a los dictados de Córdoba. El documento toledano «habla» de la capacidad y la actividad de la oligarquía provincial andalusí en pleno cenit del centralismo autoritario del Estado. La fitna estaba próxima, pero ni ella ni sus consecuencias se adivinaban.

\subsection{Capitel del Museo Arqueológico Nacional de Madrid (Inscripción n. ${ }^{\circ}$ 7-Lámina VI y figura 6) ${ }^{32}$}

Se trata de un capitel de orden compuesto, hecho en mármol blanco, que luce una magnífica talla con decoración vegetal y contario. Una de las cuatro cartelas de su ábaco ostenta la leyenda «Obra de Sa'āda al-'Āmirī» inscrita en caracteres cúficos excisos.

Evidentemente, estamos ante el autor de la pieza, un individuo llamado Sa'āda y que sería siervo o mawlà de Muhammad b. Abī 'Āmir, Almanzor, de ahí su nisba, «al-'Āmirī». Observemos que es la misma del de los Jalaf de la Mezquita Aljama de Córdoba (figura 2: f) y el Puente de Alcántara de Toledo. La pieza quedaría así datada muy probablemente entre 976 y $1002^{33}$.

Paredes" (procedencia de la financiación y destino) y sólo en cuanto a la procedencia de la financiación en Toledo.

${ }^{30}$ De bannā' deriva el español "albañil". Para las categorías de los constructores en al-Andalus omeya, véase la bibliografía contenida en la nota 10 .

31 Sobre la identificación (o no) de este último con el homónimo de la Mezquita Aljama de Córdoba y el capitel del Museo Arqueológico Nacional, véase el apartado 2.7. No se sabe (o al menos yo no sé) nada más acerca de Mūsà b. 'Alī.

32 Datos y comentarios en Souto, J. A., "¿Sa'āda = Sa'āda al-'Āmirī? (Precisiones en torno a un trabajador andalusí de la construcción)”, Al-Qanțara, XXIII (2002), 263-66.

33 Tampoco habría que descartar del todo la posibilidad de que la tal nisba se refiera a alguno de los dos hijos y sucesores de Almanzor, aunque, de entrada, la considero remota.

Al-Qanțara (AQ) XXVIII 1, enero-junio 2007, pp. 101-142 ISSN 0211-3589 
Creo que este Sa'āda al- 'Āmirī del Museo Arqueológico Nacional puede ser identificado con el Sa'āda tallista de capiteles de la Aljama cordobesa (figura 2: d). Más difícil resulta, sin embargo, su identificación con el Sa'āda «coautor» de obras de la mezquita toledana de Bāb al-Mardūm.

\subsection{Capitel doble del Museo Arqueológico de Córdoba (Inscripción n. ${ }^{\circ}$ 8-Láminas VII y VIII y figura 7)}

Otro capitel de orden compuesto, con la particularidad de ser doble o geminado. Al igual que el anterior, está muy bien tallado, con profusa decoración de motivos fitomorfos y con contarios bajo los cojinetes. En tres de las cartelas de sus ábacos exhibe sendas inscripciones, que trato como una sola por ser su soporte también una sola pieza: «Obra de Bāšir», "[Obra de] Faraŷ» y [Ob]ra de Mubārak», sin duda los tres autores materiales de la pieza ${ }^{34}$.

Ésta carece de fecha expresa, no consta que proceda de un contexto arqueológico de época 'ámirì ni ninguno de los tres nombres tiene, como en el caso anterior, la nisba correspondiente. El criterio de cronología viene dado aquí por esos solos nombres, cuyas únicas documentaciones epigráficas constructivas conocidas hasta ahora están entre los signos lapidarios de la ampliación de la Mezquita Aljama de Córdoba hecha por Almanzor (figura 2: a, c y e) ${ }^{35}$.

Hay que hacer notar que los tres nombres también aparecen escritos en obras no constructivas. Así, en el interior de la «arqueta de Leyre», hecha hacia 395/18 octubre 1004-7 octubre 1005 para 'Abd al-Malik, hijo de Almanzor, se lee «Obra de Faraŷ junto con sus discí-

34 La presencia de tres "firmas" distintas en un solo soporte plantea de nuevo la cuestión de cuál era el cometido de cada uno de los firmantes. De momento estoy convencido de que se trata de quienes tallaron el capitel, que en este caso trabajarían "a tres manos".

${ }^{35}$ Rodríguez, M. ${ }^{\text {a }}$., y Souto, J. A., "De gliptografía omeya: signos lapidarios en la Mezquita Aljama de Córdoba. Situación e índice", Actes du XI Colloque International de Glyptographie de Palma de Majorque, Braine-le-Château, 2000, 385-86 (los tres); y Souto, J. A., "De gliptografía omeya: signos lapidarios en la Mezquita Aljama de Córdoba. Ejemplares fuera del oratorio: situación y ensayo de cronología”, en Müller-Wiener, M., et al. (eds.), Al-Andalus und Europa: zwischen Orient und Okzident, Petersberg, 2004, 92-100 (Mubārak y Faraŷ). Un tallista llamado Mubārak b. Hišām, evidentemente un mawlà del califa, aunque no sé si era el mismo que Mubārak a secas, firmó un cimacio de la última ampliación del oratorio de la Aljama de Córdoba ("Situación e índice", 386).

Al-Qanțara (AQ) XXVIII 1, enero-junio 2007, pp. 101-142 ISSN 0211-3589 
pulos». Este Faraŷ sería el jefe de un taller de eboraria que funcionó durante unos cuarenta años ${ }^{36}$. Bāšir y Mubārak, por su parte, son dos de los nombres que aparecen a modo de firmas en la cerámica «verde y manganeso» de Madīnat al-Zahrā', de cronología más temprana ${ }^{37}$. No creo que se trate de los mismos individuos, pues los oficios de tallista de piedra, tallista de marfil y ceramista -0 , al menos, pintor de cerámica - son muy distintos. Volvemos al asunto, no resuelto de momento, de si estos nombres que aparecen en objetos tan diversos identifican a individuos homónimos, a talleres o a jefes de talleres, sin que unas posibilidades excluyan a las otras ${ }^{38}$.

Por lo tanto, y mientras no haya argumentos irrebatibles en sentido contrario, propongo identificar a los autores de este capitel con los tallistas de piezas de columnas de la Mezquita Aljama de Córdoba y situar esta pieza en el período de gobierno de Almanzor.

\subsection{Capitel del Ayuntamiento de Sanlúcar de Barrameda (Inscripción n. ${ }^{\circ}$ 9-Lámina IX y figura 8$)^{39}$}

En la fachada neomudéjar del Palacio de Orleáns Borbón (1852), hoy sede del Ayuntamiento de Sanlúcar de Barrameda (Cádiz), hay reutilizados dos capiteles omeyas de mármol de magnífica talla y en relativo buen estado de conservación ${ }^{40}$. Uno de ellos, de orden corin-

36 Última publicación de esta arqueta, con bibliografía y magníficas fotografías, en Bango Torviso, I. (dir.), Sancho el Mayor y sus herederos. El linaje que europeizó los reinos hispanos, I, Pamplona, 2006, n. ${ }^{\circ} 149$.

${ }_{37}$ Cano Piedra, C., La cerámica verde-manganeso de Madinat al-Zahra, Granada, 1996, fig. 64: SA/456 (Bāšir); y SA/361, SA/367 y SA/402 (Mubārak).

38 Consideraciones al respecto en "Documentation de noms propres" y "De gliptografía omeya: el nombre de Fath", pas.

39 Quiero dejar constancia de mi agradecimiento al Excmo. Ayuntamiento de Sanlúcar de Barrameda, y muy especialmente a D. Marco Antonio Oliva, por la ayuda prestada al hacer la toma de datos de este capitel (3 de abril de 2006), así como por la bibliografía sobre el palacio, hasta entonces desconocida para mí.

40 Sobre este edificio, véase VV. AA., El Palacio Orleáns Borbón de Sanlúcar de Barrameda, Sanlúcar de Barrameda, 1989. Los capiteles se comentan en la p. 113, y en la primera hay una fotografía del que nos ocupa. Sobre la reutilización de capiteles omeyas en edificios posteriores, véase Cressier, P., y Cantero Sosa, M., "Diffusion et remploi des chapiteaux omeyyades après la chute du califat de Cordoue. Politique architecturale et architecture politique", VI Colloque international. L'Afrique du Nord antique et médiévale. Productions et exportations africaines. Actualités archéologiques, París, 1995, 159-75, así como Cressier, P., "Les dépouilles du califat. Remploi des chapiteaux omey- 
tio, tiene inscrita en su cartela la leyenda «Obra de Mubārak», sin duda su autor.

No hay nada que añadir a lo ya dicho en párrafos anteriores acerca de la documentación de este nombre en la epigrafía omeya andalusí. Por otra parte, la firma de este capitel de Sanlúcar es gráficamente idéntica a la del que se conserva en el Museo de Córdoba, de ahí que opine que se debe a la misma mano. Las diferencias formales de ambos soportes no hacen sino confirmar la variedad de «modelos» que un solo tallista, o al menos un solo taller, era capaz de producir, tanta como encargos recibiera.

\subsection{Capitel de la Mezquita de la Qașba de Marrakesh (Inscripción n. ${ }^{\circ}$ 10-Lámina X)}

La idea de la legitimidad de la soberanía de los Omeyas, y con ella sus formas de expresión, trascendió sus fronteras espacio-temporales. Así, los Almohades, en su propio afán legitimista, no dudaron en reutilizar piezas arquitectónicas omeyas o tenidas por omeyas en sus edificios más emblemáticos de al-Andalus y el Magreb, exhibiéndolas en puntos clave de ellos a modo de auténticos «trofeos» ${ }^{41}$, lo que tiene sus primeros precedentes en el Islam temprano, con la reutilización programática de materiales clásicos ${ }^{42}$.

Es en tal contexto donde hay que situar este capitel, hoy día nada menos que en el mihrab de la Mezquita de la Qașba de Marrakesh. Es una pieza de mármol, de orden compuesto, muy bien tallada con de-

yades cordouans en Méditerranée médiévale, islamique et chrétienne", en el coloquio Pratiques du remploi au Moyen Âge dans les pays de la Méditerranée occidentale ( $X^{e}-X I I I^{e}$ siècles), coordinado por P. Toubert y celebrado en la Casa de Velázquez (Madrid) en marzo de 2006, en prensa. Obsérvese, a propósito del capitel de Sanlúcar, que esta reutilización intencionada de materiales arquitectónicos omeyas llega a la época “contemporánea".

41 Véase la nota anterior.

42 Desde la Cúpula de la Roca y la Mezquita Aljama de Damasco a las dos primeras fases de la Mezquita Aljama de Córdoba en la arquitectura religiosa. Sobre la reutilización de materiales preislámicos en este último edificio, véanse principalmente Ewert, C. y Wisshak, J. P., Forschungen zur almohadischen Moschee., pas., y Cressier, P., "Les chapiteaux de la grande mosquée de Cordoue (oratoires d' Abd ar-Rahmān I et d' Abd ar-Rahmān II) et la sculpture de chapiteaux à l'époque émirale. Première partie”, Madrider Mitteilungen, 25 (1984), 216-81 (segunda parte en el volumen 26 (1985), 257-313, de la misma revista).

Al-Qanțara (AQ) XXVIII 1, enero-junio 2007, pp. 101-142 ISSN 0211-3589 
coración vegetal y contario. En una de sus cartelas figura inscrito el sintagma «Obra de Jayra» ${ }^{43}$.

Hay que dar la razón a Ocaña cuando considera que se trata de la misma firma que figura en fustes de la ampliación de la Aljama de Córdoba hecha por Almanzor (figura 2: b), lo que contribuiría a datar la pieza en su etapa de gobierno ${ }^{44}$.

\subsection{Lápida del Instituto de Valencia de Don Juan (Inscripción n. ${ }^{\circ}$ 11-Lámina XI y figura 9)}

Se trata de un fragmento de lápida de mármol blanco escrita en cúfico simple de resalto. No conserva la fecha ${ }^{45}$.

Aun así, queda suficiente texto como para deducir que conmemora una construcción, pero no de qué construcción se trataba - aparece el verbo amara, "ordenó», ya no su objeto-, y para conocer al sujeto de su orden, al-Mu'ayyad bi-llāh, es decir, Hišām II. He ahí lo verdaderamente importante de esta pieza: es la única inscripción constructiva conocida con el nombre de este califa y donde aparece como ordenante. En las otras dos que lo mencionan, la de la azacaya de Écija y la del Puente de Alcántara de Toledo, las órdenes están a nombre de su madre y de Almanzor, respectivamente.

$\mathrm{Al}$ igual que ocurre con los capiteles de los apartados anteriores, he de reconocer que la falta de fecha impide atribuir con precisión esta lápida a la época de Almanzor y no a la de uno de sus hijos, que mantuvieron a Hišām II en el califato. La lectura de Lévi-Provençal lo llevó a considerar que los «dos fatàs» de la línea 5 serían Fā'iq al-Nizāmī y Ŷawḍar, con lo que la inscripción quedaría datada entre 366 y 367/976 y 977, año éste de la muerte del segundo por orden de Almanzor ${ }^{46}$. No me atrevo yo a tanto.

43 Sobre el capitel, véase Ewert, C., y Wisshak, J. P., "Forshungen zur almohadischen Moschee. III. Die Qașba-Moschee in Marrakech", Madrider Mitteilungen, 28 (1987), nota 132 (donde se recoge bibliografía anterior) y lámina 52.

${ }^{44}$ Ewert, C. y Wisshak, J. P., "Forshungen zur almohadischen Moschee. III", nota 132. La firma se encuentra en tres fustes: "Situación e índice", 385.

${ }_{45} \mathrm{Su}$ historia debió de ser dura: dos huellas de goznes en el reverso permiten deducir que fue reutilizada como gorronera o quicialera.

${ }^{46}$ Lévi-Provençal, É., Inscriptions arabes d'Espagne, Leiden-París, 1931, n. ${ }^{o} 20$. 


\section{Conclusiones}

Como se puede ver, la «colección diplomática» compuesta por las inscripciones constructivas de la época del gobierno de Almanzor es tan breve como selecta e ilustrativa ${ }^{47}$. Comprende una dispersión geográfica notable y una gran variedad tipológica. Así, puede ordenarse por tipos de edificio documentados (religiosos — que incluyen la mezquita aljama de la capital del país, una mezquita de barrio de capital «de provincias» y una mezquita rural- , civiles, militares ${ }^{48} \mathrm{y}$ desconocidos), tipos de iniciativa (desconocida, oficial y privada, y dentro de la oficial, por orden del califa, de su madre y de Almanzor), ámbitos geográficos (urbano y rural), tipos de público a quien van dirigidas (trabajadores de una obra constructiva y público en general), funciones (constancia de trabajo hecho y conmemoración o propaganda), tipos de soporte (lápida lujosa, lápida pobre, friso y elementos de columnas), tipos de escritura (árabe - dentro de ella, cúfica y cursiva- y latina), tipos diplomáticos (documento con información completa, documento con información escueta y simples nombres de autores, con matices para cada caso)...

También merece la pena destacar que los materiales presentados aquí son suficientes en número y gozan de la calidad necesaria como para recordarnos que el estudio de «las inscripciones en sí» carece de sentido si se desea leer en ellas algo más que palabras esculpidas: todo documento procede de un contexto claro y preciso, fuera del cual pierde buena parte de su significado, y las inscripciones no son excepciones de esta regla. Esto se aprecia de forma diáfana al considerar, por ejemplo, el contexto físico y comparar la información suministrada por epígrafes in situ, o cuya obra documentada se ha conservado mejor o peor, con la de aquellos en otras condiciones: ¡cuánto daríamos por contemplar lo que ordenó hacer Subh en la azacaya de Écija!, por no decir lo que Hišām II en ni siquiera sabemos dónde ni exactamente cuándo... Junto con la elocuencia de la inscripción del «Cristo de la Luz», su edificio nos ayuda a «redondear» el mensaje que transmite, mientras que la reformada o reparada mezquita de «Las Paredes» espera su exhumación para darse a conocer material-

\footnotetext{
${ }^{47}$ Lo de "breve" es relativo: recuérdese que los signos lapidarios epigráficos de la Mezquita Aljama de Córdoba son muy numerosos.

${ }^{48}$ Me refiero a la n. ${ }^{\circ} 4$, ya que los puentes son obras tanto civiles como militares.
}

Al-Qanțara (AQ) XXVIII 1, enero-junio 2007, pp. 101-142 ISSN 0211-3589 
mente. En medio del tiránico «silencio» constructivo impuesto en la última fase de la Aljama cordobesa, sus hacedores parecen «colarse» para susurrar a la posteridad sus nombres y algo más...

Lo mismo cabe apuntar acerca del contexto cronológico: son varias las inscripciones sin fecha y fechables en la segunda mitad o incluso en el último tercio del siglo X, pero cuya atribución al lapso preciso 976-1002 no resiste una crítica medianamente severa. ¡Cómo me gustaría poderlas integrar en un mismo «lote» con las que presento aquí! ¿Y qué decir del contexto productivo? La comparación de las inscripciones constructivas con las de los «complementos arquitectónicos» y los objetos «personales» del período se hace obligada para entender muchas cosas y está en buena medida pendiente. Pero habrá de quedar para otra ocasión... 


\section{APÉNDICE: CATÁLOGO DE INSCRIPCIONES}

\section{Inscripción $n^{0} 1$}

Resumen: Conmemoración de la [re]construcción de una azacaya.

Cronología: $R a b \bar{l}$ ‘ II 367 / 16 noviembre - 14 diciembre 977.

Soporte: Lápida.

Material: Mármol.

Dimensiones en centímetros: Altura: 63; anchura: 51.

Tipo de letra: Cúfico florido.

Procedencia: Écija.

Ubicación actual: Iglesia de Santa Cruz de Écija (fachada principal de la torre, a unos 2,5 m de altura).

Ubicación original: Desconocida.

Bibliografía: Conde, J. A., Historia de la dominación de los árabes en España, I, Madrid, 1820, p. 496 (reproducción - grabado- y traducción); Amador de los Ríos y Villalta, R., Inscripciones árabes de Sevilla (Madrid, 1875), Apéndice II, $\mathrm{n}^{\circ} 2$; Lévi-Provençal, É., Inscriptions arabes d'Espagne (LeidenParís, 1931), n 30; Combe, É., Sauvaget, J., \& Wiet, G., Répertoire Chronologique d'Épigraphie Arabe, V (El Cairo, 1934), nº 1873 (colaboración de Lévi-Provençal); Souto, J. A., "Las inscripciones árabes de la iglesia de Santa Cruz de Écija (Sevilla): dos documentos emblemáticos del Estado omeya andalusí', $A l$ Andalus-Magreb, 10 (2002-2003), $\mathrm{n}^{\circ} 2$.

Texto:

$$
\begin{aligned}
& 1 \\
& 2 \text { امرت ببنيان هذه السقاية السيد } 1 \text { السيم الرحن }
\end{aligned}
$$

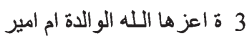

$$
\begin{aligned}
& 4 \text { المؤمنين المؤيد باللـه هشام الله الوام المير } \\
& 5 \text { بن الحكم اطل الله بقاءه رجاء } 5
\end{aligned}
$$

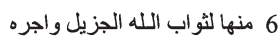

$$
\begin{aligned}
& 7 \text { العظيم فتمت بعون الله وتايده } 8 \\
& 8 \text { على يدى صنيعتها صاحب الشرطة }
\end{aligned}
$$

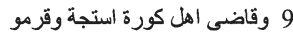

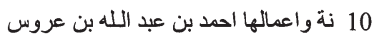

$$
\begin{aligned}
& 11 \text { وذلك فى شهر ربيع الاخر من سنت سبع وستين وثلث عند } \\
& 12
\end{aligned}
$$

\section{Traducción:}

${ }^{1}$ En el nombre de Dios, el Clemente, el Misericordioso. $/ 2$ Ordenó la [re]construcción de esta azacaya la Sayyid ${ }^{3} a$-glorifíquela Dios-al-Wālida, Madre del Emir ${ }^{4}$ de los Creyentes, al-Mu'ayyad bi-llāh Hišām $/ 5$ b. al-Hakam - prolongue Dios su permanencia (en esta vida)—, esperando $/ 6$ por ella la generosa recompensa de Dios y Su retribución $/ 7$ magnífica. Y fue terminada con el auxilio de Dios y Su 
protección /8 bajo la dirección de su șan̄i'a, șạhib al-šurța $/ 9$ y cadí de las gentes de la cora de Écija y Carmo/ ${ }^{10}$ na y sus 'amales, Aḥmad b. 'Abd Allāh b. 'Arūs. /11 Ello en el mes de rabī' II del año siete y sesenta y tres/12cientos (367 / 16 noviembre - 14 diciembre 977).

Anomalías y peculiaridades gráficas:

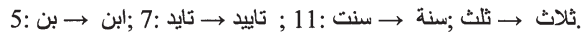

\section{Variantes de edición:}

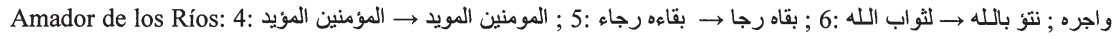

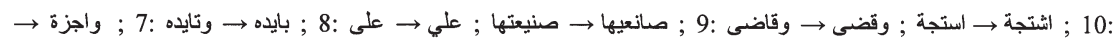

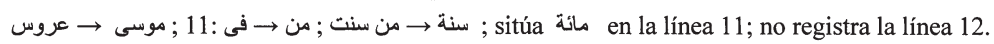

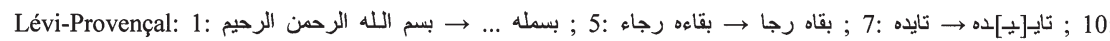

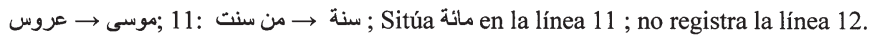

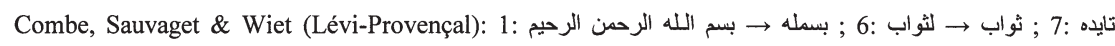

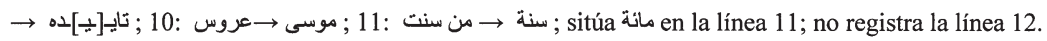

\section{Variantes de traducción / interpretación:}

Conde: $2:$ azacaya $\rightarrow$ azequia ; 2/3: al-Sayyida $\rightarrow$ la Señora ; 3: al-Wãlida $\rightarrow$ [no lo traduce] ; 8/9 bajo la dirección de su șanī'a, șâhib al-šurța y cadí de las gentes de la cora $\rightarrow$ por manos de su artífice, y prefecto Sahib Xarta, cadi de los pueblos de la cora ó comarca ; 10: 'amales $\rightarrow$ dependencias de su gobierno; 'Arūs $\rightarrow$ Muza.

Amador de los Ríos: 2: azacaya $\rightarrow$ as-sequia ; 2/3: al-Sayyida $\rightarrow$ la Señora ; 3: al-Wälida $\rightarrow$ [no lo traduce] ; 8: șan̄' $a \rightarrow$ arquitecto ; 9/10: Écija y Carmona y sus 'amales, Ahmad b. 'Abd Allāh b. 'Arūs $\rightarrow$ Asticha (Écija) y Carmona. La hizo Ahmed-ben-Abdil-Láh-ben-Musa ; 11: 16 noviembre - 14 diciembre $977 \rightarrow$ (367 H.-979 J. C.)

Lévi-Provençal: $2:$ azacaya $\rightarrow$ fontaine ; 2/3: al-Sayyida $\rightarrow$ la dame ; 3: al-Wālida $\rightarrow$ la «validé»; 7: Su magnífica $\rightarrow$ une magnifique ; 8/9: su șañ̄' $a$, šāhib al-šurța y cadí de las gentes de la cora $\rightarrow$ son protégé, le préfet de police et le ḳāḍi de la population du district ; 10: 'amales $\rightarrow$ dépendances ; 'Arūs $\rightarrow$ Mūsā.

Combe, Sauvaget \& Wiet (Lévi-Provençal): 1: En el nombre de Dios, el Clemente, el Misericordioso $\rightarrow$ $\mathrm{xxx} ; 2$ : azacaya $\rightarrow$ fontaine ; 2/3: al-Sayyida $\rightarrow$ la dame ; 3: al-Wãlida $\rightarrow$ la mère ; 8/9: bajo la dirección de su șañ̄ $a$, șăhib al-šurța y cadí de las gentes de la cora $\rightarrow$ par les mains de son obligé, le préfet de police et kāọī du cercle.

Ilustraciones: Fotografía y dibujo: J. A. Souto. 


\section{Inscripción $n^{0} 2$}

Resumen: Signos lapidarios epigráficos.

Cronología: Ca. 381-84 / 991-94.

Soportes: Elementos de columnas (basas, fustes, capiteles y cimacios).

Materiales: Piedras pulimentables de diversos tipos.

Dimensiones en centímetros: Variables.

Tipos de letras: Cúfico y cursivo (árabes); capital sentado (latinas).

Procedencia: Córdoba.

Ubicación actual: In situ (oratorio de la Catedral de Córdoba) y descontextualizados (oratorio y patio de la Catedral de Córdoba; casa ${ }^{\circ} 1$ de la plaza de Santa Catalina, Córdoba).

Ubicación original: Mezquita Aljama de Córdoba.

Bibliografía: Ocaña Jiménez, M., "Arquitectos y mano de obra en la construcción de la gran mezquita de Occidente", Cuadernos de la Alhambra, 22 (1986), pp. 55-85; Nieto Cumplido, M., La Catedral de Córdoba (Córdoba, 1998), pássim; Rodríguez, Ma J., \& Souto, J. A., "De gliptografía omeya: signos lapidarios en la Mezquita Aljama de Córdoba. Situación e índice", Actes du XIe Colloque International de Glyptographie de Palma de Majorque (Braine-le-Château, 2000), pp. 359-91; Souto, J. A., "De gliptografía omeya: signos lapidarios en la Mezquita Aljama de Córdoba. Ejemplares fuera del oratorio: situación y ensayo de cronología", en M. Müller-Wiener \& Al., eds., Al-Andalus und Europa: zwischen Orient und Okzident (Petersberg, 2004), pp. 92-100.

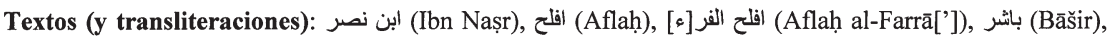

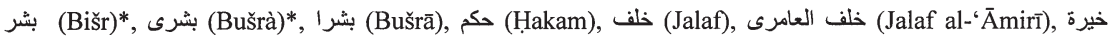

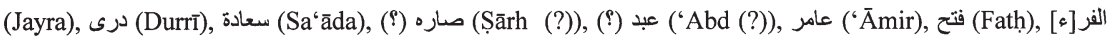
(Al-Farrā[']), مرج (Faraŷ), مبارك (Kuāh), مبارك بن هشام (Mubārak b. Hišām), مسعود (Mas'ūd)*,

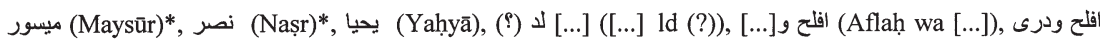
(Aflaḥ wa Durrī), عمل افلح ('amal Aflah), عمل بلح ورزق ('amal Bišr), عمل فتح ('amal Fath), E, I, O, S, T, rul-1,

Observaciones: Los nombres árabes marcados con * aparecen también escritos «a la inversa». Las letras latinas $\mathrm{E}, \mathrm{I}, \mathrm{O}$ y S aparecen aisladas o en combinación unas con otras, a veces entre dos líneas. Algunos de estos signos pueden verse reproducidos en "Arquitectos y mano de obra", y todos editados en "Situación e índice".

Ilustraciones: Dibujos: J. A. Souto.

Al-Qanțara (AQ) XXVIII 1, enero-junio 2007, pp. 101-142 ISSN 0211-3589 


\section{Inscripción $n^{0} 3$}

Resumen: Firma en un capitel.

Cronología: Ca. 381-84 / 991-94.

Soporte: Cartela de ábaco de capitel compuesto.

Material: Mármol.

Dimensiones en centímetros: Desconocidas.

Tipo de letra: Cúfico simple.

Procedencia: Córdoba.

Ubicación actual: In situ.

Ubicación original: Columna izquierda de la ventana derecha de la puerta de San Juan de la Catedral de Córdoba.

Bibliografía: Brisch, K., "Sobre un grupo de capiteles y basas islámicas del siglo XI de Toledo", Cuadernos de la Alhambra, 15-17 (1979-81), p. 162 y lám. XVI a.

Texto: عمل بن \بدر

Traducción: Obra de [I]bn / Badr.

Anomalías y peculiaridades gráficas: ابن ج بن .

Ilustración: Fotografía: J. A. Souto.

\section{Inscripción $n^{\circ} 4$}

Resumen: Conmemoración de obras de construcción de un puente.

Cronología: 387 / 14 enero 997 - 2 enero 998.

Soporte: Lápida (?).

Material: Desconocido.

Dimensiones en centímetros: Desconocidas.

Tipo de letra: Desconocido.

Procedencia: Toledo.

Ubicación actual: Original perdido. Se conserva su resumen-traducción parcial en una inscripción romance de 1259, reparada en 1575, sobre la fachada exterior de la torre interior del Puente de Alcántara (Toledo).

Ubicación original: Desconocida (en el Puente de Alcántara de Toledo).

Bibliografía: Rodríguez, Ma J., \& Souto, J. A., "De Almanzor a Felipe II: la inscripción del Puente de Alcántara de Toledo (387 / 997-998) y su curiosa historia", Al-Qantara, XXI (2000), pp. 185-209. 
Texto:

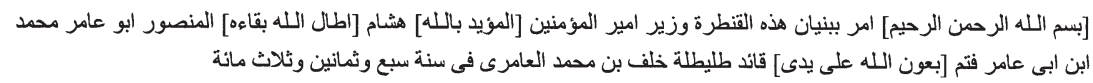

\section{Traducción:}

[En el nombre de Dios, el Clemente, el Misericordioso.] Ordenó la [re]construcción de este puente el wazīr del Emir de los Creyentes, [al-Mu'ayyad bi-llāh] Hišām [—prolongue Dios su permanencia (en esta vida)-], al-Manșūr Abū 'Āmir Muhammad b. Abī 'Āmir. Y se terminó [con el auxilio de Dios bajo la dirección] del $q \bar{a}$ ’’ de Toledo Jalaf b. Muhammad al-'Āmirī en el año siete y ochenta y trescientos (387 / 4 enero 997 - 2 enero 998).

Ilustraciones: Fotografía: J. A. Souto; edición: Rodríguez \& Souto.

\section{Inscripción $\mathbf{n}^{0} 5$}

Resumen: Conmemoración de reparación o reforma de una mezquita rural.

Cronología: $\breve{S} a$ 'bān 387 / 9 agosto - 6 septiembre 997 ó 389 / 18 julio - 15 agosto 999.

Soporte: Lápida.

Material: Pizarra.

Dimensiones en centímetros: Anchura máxima 107; altura máxima: 38; grosor: 17.

Tipo de letra: Cursivo.

Procedencia: Yacimiento de «Las Paredes» (Logrosán, Cáceres).

Ubicación actual: Museo «Casa tradicional» (Logrosán, Cáceres).

Ubicación original: Desconocida.

Bibliografía: Gilotte, S., González, A., \& Souto, J. A., "L'Inscription d'époque omeyyade de la mosquée de "Las Paredes" (Logrosán, Cáceres, Espagne)", Archéologie Islamique, 10 (2000), pp. 55-64.

Texto:

$$
\begin{aligned}
& 1 \\
& 2 \text { اصلح هاذا المسجد فى شعبان [سن]- [سب] \ـع] [تع وثمانين وثلث مئة }
\end{aligned}
$$

\section{Traducción:}

1 [...] con sus riquezas para las gentes de (?) la explanada la adquirió $w d w$ [...] $l b(?)$ 'ldhr (?) [...]

2 Reparó esta mezquita en ša 'bän del [añ]o [siet]e / [nuev]e y ochenta y trescientos (387 ó 389 / 9 agosto - 6 septiembre 997 ó 18 julio - 15 agosto 999).

Al-Qanțara (AQ) XXVIII 1, enero-junio 2007, pp. 101-142 ISSN 0211-3589 
Anomalías y peculiaridades gráficas:

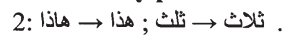

Ilustraciones: Fotografía y dibujo: J. A. Souto.

\section{Inscripción $n^{0} 6$}

Resumen: Conmemoración de la construcción de una mezquita urbana.

Cronología: Muharram 390/13 diciembre 999 - 11 enero 1000.

Soporte: Friso.

Material: Ladrillo.

Dimensiones en centímetros: Longitud: 765 ; altura: 37.

Tipo de letra: Cúfico simple.

Procedencia: Toledo.

Ubicación actual: In situ.

Ubicación original: Friso superior de la fachada occidental de la mezquita de Bāb al-Mardūm, hoy iglesia del «Cristo de la Luz» (Toledo).

Bibliografía: Amador de los Ríos y Villalta, R., La ermita del Santo Cristo de la Luz en Toledo (Madrid, 1899), p. 25; Ídem, Monumentos arquitectónicos de España. Toledo (Madrid, 1905), p. 80; LéviProvençal, É., Inscriptions arabes d'Espagne (Leiden-París, 1931), nº 50 (reseña); Combe, É., Sauvaget, J., \& Wiet, G., Répertoire Chronologique d'Épigraphie Arabe, V (El Cairo, 1934), nº 1822bis (reseña de Lévi-Provençal)); Ocaña Jiménez, M., "La inscripción fundacional de la mezquita de Bīb al-Mardūm en Toledo", Al-Andalus, XIV (1949), pp. 175-83; Ídem, El cúfico hispano y su evolución (Madrid, 1970), ${ }^{\circ}$ 28; Souto, J. A., "Epigraphy and building in Umayyad al-Andalus: genesis and prospects for a research project", en Vermeulen, U., \& De Smet, D., eds., Philosophy and Arts in the Islamic World. Proceedings of the Eighteenth Congress of the UEAI (Orientalia Lovaniensia Analecta, 87, Lovaina, 1998), pp. 303$24, \mathrm{n}^{\circ} 2$.

Texto:

$$
\text { وسعم الله الرحمن الرحيم اقام هاذا المسجد ا[حمد] ابن حديدى من مله ابتغاء ثو اب الله فتما بعون الله على يدى موسا ابن على البناء }
$$

\section{Traducción:}

En el nombre de Dios, el Clemente, el Misericordioso. Erigió esta mezquita A[hmad] b. Ḥadīdī, de su peculio, deseando la recompensa ultraterrena de Dios. Se concluyó, con el auxilio de Dios, bajo la dirección de Mūsà b. 'Alī, el constructor, y de Sa'āda. Fue terminada en muharram del año noventa y trescientos (390/ 13 diciembre 999 - 11 enero 1000). 
Anomalías y peculiaridades gráficas:

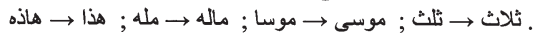

Anomalías morfosintácticas:

فتم $\rightarrow$ فتما

Variantes de edición:

Edición de Amador de los Ríos, 1899:

بسم الله المرحمن الرحيم اقام ذلكا المسجد ا... انجديد عل ملة ابتغا بوبا بنية فتما بعون الله على يدى موسا ابن على البناء وسعادن وتم فى المحرم سنة سبعين وثلث ماية

Edición de Amador de los Ríos, 1905:

$$
\text { سنة الله الرحمن الرحيم اقام ذلك المسجد ا... التجديد اعلى منه ابتغا بواب بنيه فتم بعون اللها على يدى موسا ابن على البناء وسعادة وتم }
$$

Souto:

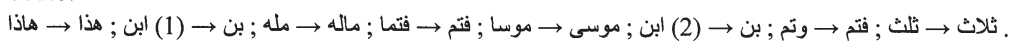

\section{Variantes de traducción / interpretación:}

Traducción de Amador de los Ríos, 1899: ¡En el nombre de Alláh, el Clemente, el Misericordioso! Fué erigida esta Mezquita... adherida á la primitiva firmemente en la disposición de la obra, y se terminó con el auxilio de Alláh, bajo la dirección (por manos) de Musa-Ibn-Aly, el arquitecto, y de Saâdam. Fué concluída en Al-Moharram del año setenta y trescientos.

Amador de los Ríos, 1905: Erigió $\rightarrow$ Fue reconstruída; A[hmad] b. Hadīdī, de su peculio, deseando la recompensa ultraterrena de Dios $\rightarrow$... renovación de la parte superior de ella, proponiéndose hacer hermosa su obra; Se concluyó $\rightarrow$ se terminó (la restauración); noventa y trescientos $\rightarrow$ setenta y trescientos.

Ilustraciones: Fotografía: Instituto Arqueológico Alemán, negativo PLF 2699 (P. Witte); dibujo: Ocaña, 1949.

\section{Inscripción $\mathbf{n}^{0} 7$}

Resumen: Firma en un capitel.

Cronología: Gobierno de Almanzor (976-1002).

Soporte: Cartela de ábaco de capitel compuesto.

Material: Mármol.

Al-Qanțara (AQ) XXVIII 1, enero-junio 2007, pp. 101-142 ISSN 0211-3589 
Dimensiones en centímetros: Altura: 25; longitud del ábaco: 27,5; diámetro de la base: 14. Cartela: longitud superior: 6,5 ; longitud inferior: 6 ; altura: 3,8 .

Tipo de letra: Cúfico simple.

Procedencia: Córdoba (?).

Ubicación actual: Museo Arqueológico Nacional (Madrid).

No de inventario: $2001 / 151 / 1$.

Ubicación original: Desconocida.

Bibliografía: Anónimo, Importante colección internacional procedente de una antigua familia de la nobleza (catálogo de "Fernando Durán Subastas", subasta del 12 de diciembre de 2001, Madrid, s.f. [2001]), n 34; Souto, J. A., "¿Sa'āda = Sa‘āda al-'Āmirī? (Precisiones en torno a un trabajador andalusí de la construcción)", Al-Qantara, XXIII (2002), pp. 263-66.

Texto: عـ[مل سعادة العمراى].

Traducción: [O]bra de Sa‘̄â/da al-'Āmir/̄̄.

Anomalías y peculiaridades gráficas: العامرى ج العمرى .

Variantes de edición: Anónimo: no lo edita.

Variantes de traducción / interpretación: Traducción de Anónimo: «Alá es el más grande».

Ilustraciones: Fotografía y dibujo: J. A. Souto.

\section{Inscripción $n^{0} 8$}

Resumen: Tres firmas en un capitel.

Cronología: Gobierno de Almanzor (976-1002).

Soporte: Tres cartelas de ábaco de capitel doble compuesto.

Material: Mármol blanco.

Dimensiones en centímetros: Capitel: altura: 38; anchura total del ábaco: 68; diámetro de cada base: 25 . Cartela derecha: altura: 5; anchura de la base: 9,5. Cartela izquierda: altura: 5,5; anchura de la base: 9,5. Cartela lateral derecha: altura: 5; anchura máxima conservada: 7.

Tipo de letra: Cúfico simple.

Procedencia: Córdoba.

Ubicación original: Desconocida.

Ubicación actual: Museo Arqueológico Provincial de Córdoba.

Número de inventario: 28.529 .

Bibliografía: Inédito (?).

Texto: Cartela derecha: عمل \باشر ; cartela izquierda: عمل] \مرج] ; cartela lateral derecha:

Traducción: Cartela derecha: Obra de / Bāšir; cartela izquierda: [Obra de] / Faraŷ; cartela lateral derecha: 
[Ob]ra de Mubāra/k.

Ilustraciones: Fotografías y dibujos: J. A. Souto.

\section{Inscripción $\mathbf{n}^{\circ} 9$}

Resumen: Firma en un capitel.

Cronología: Gobierno de Almanzor (976-1002).

Soporte: Cartela de capitel corintio.

Material: Mármol blanco.

Dimensiones en centímetros: Capitel: altura conservada: 22,5; anchura del ábaco: 27; diámetro de la base: 19,5. Cartela: altura conservada: 5 ; anchura de la base: 7 .

Tipo de letra: Cúfico simple.

Procedencia: Desconocida (¿Córdoba?).

Ubicación original: Desconocida.

Ubicación actual: Puerta de la fachada del Ayuntamiento de Sanlúcar de Barrameda (Cádiz), rematando la columna izquierda.

Bibliografía: VV.AA., El Palacio Orleáns Borbón de Sanlúcar de Barrameda (Sanlúcar de Barrameda, 1989), p. 113 y fotografía.

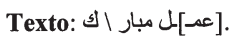

Traducción: Obra de Mubāra/k

Variantes de edición: VV.AA.: no lo editan.

Variantes de traducción / interpretación: VV.AA.: no lo traducen.

Ilustraciones: Fotografía y dibujo: J. A. Souto

\section{Inscripción $n^{\circ} 10$}

Resumen: Firma en un capitel.

Cronología: Gobierno de Almanzor (976-1002).

Soporte: Cartela de capitel compuesto.

Material: Mármol.

Dimensiones en centímetros: Desconocidas.

Tipo de letra: Cúfico simple. 
Procedencia: Córdoba (?).

Ubicación actual: Mezquita de la Qașba de Marrakesh (reutilizado en la columna sur del lado oeste del mihrab).

Ubicación original: Desconocida.

Bibliografía: Texto y traducción de M. Ocaña, en Ewert, C., \& Wisshak, J. P., "Forshungen zur almohadischen Moschee. III. Die Qașba-Moschee in Marrakech", Madrider Mitteilungen, 28 (1987), nota 132.

Texto: عمل اخيرة

Traducción: Obra / de Jayra.

Variantes de edición: Ocaña: خيرةّ ج خيرة.

Variantes de traducción / interpretación: Ocaña: Jayra $\rightarrow$ Jĩra.

Ilustración: Fotografia: C. Ewert.

\section{Inscripción $n^{\circ} 11$}

Resumen: Conmemoración de obras de construcción.

Cronología: 366-99 / 976-1009 (califato de Hišām II).

Soporte: Fragmento de lápida.

Material: Mármol.

Dimensiones en centímetros: Altura máxima conservada: 39; anchura máxima conservada: 30; grosor: 6,5 .

Tipo de letra: Cúfico simple.

Procedencia: Córdoba (?).

Ubicación actual: Instituto de Valencia de Don Juan (Madrid).

Número de inventario: 5266.

Ubicación original: Desconocida.

Bibliografía: Codera, F., "Fragmento de inscripción árabe", Boletín de la Real Academia de la Historia, XLVI (1905), p. 451 (noticia); Lévi-Provençal, E., Inscriptions arabes d'Espagne, Leiden-París, 1931, $\mathrm{n}^{\circ}$ 20; Combe, É., Sauvaget, J., \& Wiet, G., Répertoire Chronologique d'Épigraphie Arabe, V, El Cairo, 1934, nº 1872 (colaboración de Lévi-Provençal).

Texto:

$$
\begin{aligned}
& \text {.... } \\
& \text {...] }] \text { [...2 } 2 \\
& 3
\end{aligned}
$$

Al-Qanțara (AQ) XXVIII 1, enero-junio 2007, pp. 101-142 ISSN 0211-3589 


$$
\begin{aligned}
& 4 \text { امر الامام المؤيد ...] } \\
& 5 \text { امير المؤمنين وســ... } \\
& \text { [... } 6
\end{aligned}
$$

\section{Traducción:}

$\left[\ldots \beta^{\beta} \ldots\right.$ al-Muș]ṭaāa y $[\mathrm{su}] \operatorname{am}[\bar{i} n$...] $/ 4$ Ordenó el imán al-Mu'a[yyad bi-llāh...] $/ 5$ Emir de los Creyentes y .. $[\ldots / 6 \ldots]$.

Anomalías y peculiaridades gráficas:

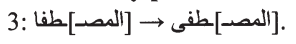

\section{Variantes de edición:}

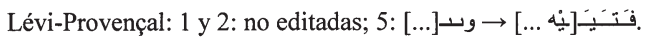

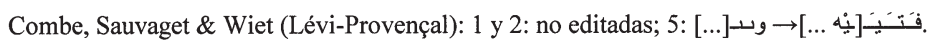

Variantes de traducción / interpretación:

Lévi-Provençal: $5:$ y .. [...] $\rightarrow$ à ses deux officiers...

Combe, Sauvaget \& Wiet (Lévi-Provençal): 5: y .. [... ] $\rightarrow$ à [ses deux] serviteurs...

Ilustraciones: Fotografía y dibujo: J. A. Souto. 
LÁMINA I.- Inscripción n. $^{\circ} 1$

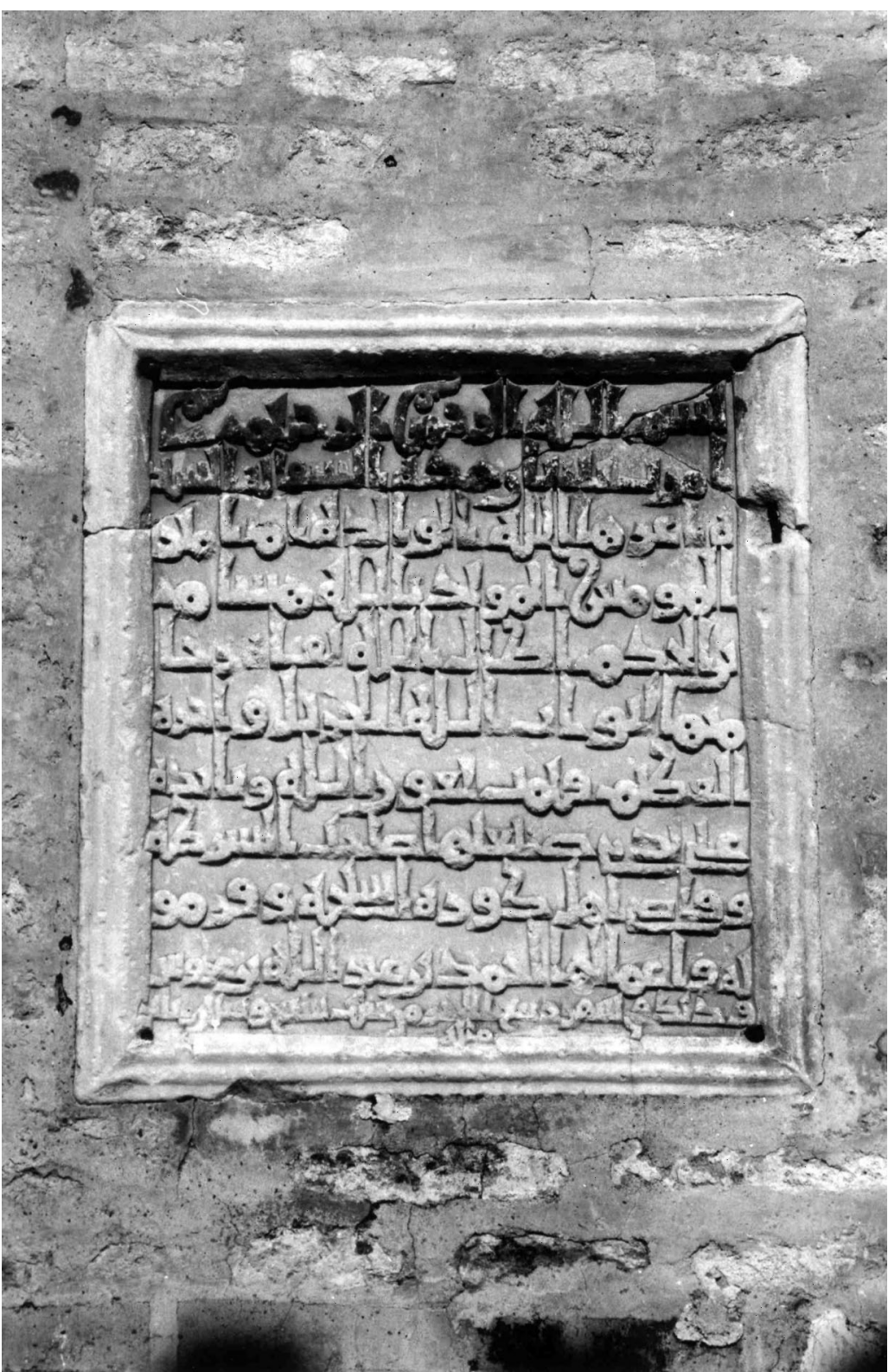

Al-Qanțara (AQ) XXVIII 1, enero-junio 2007, pp. 101-142 ISSN 0211-3589 
LÁMINA II.--Inscripción n.$^{0} 3$

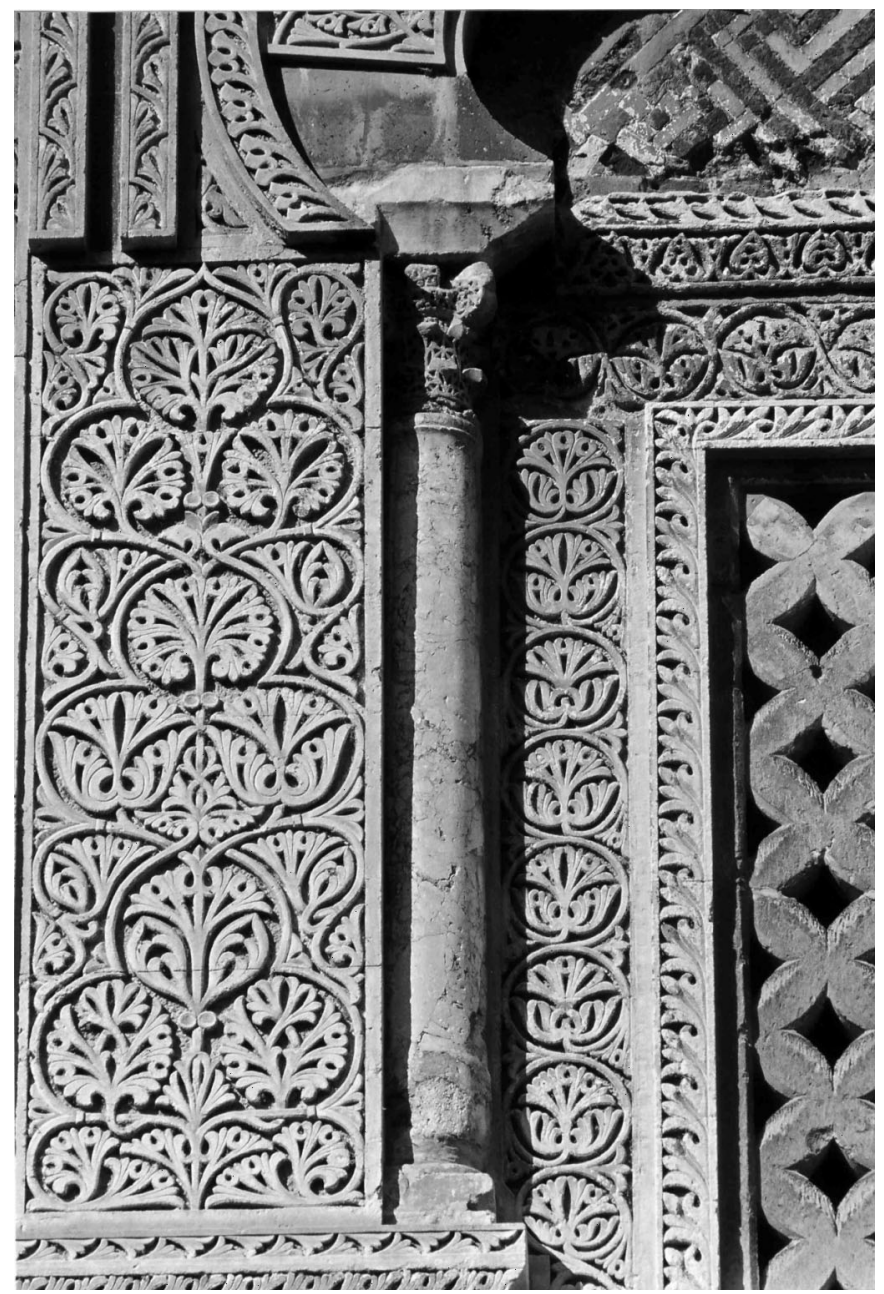

Al-Qantara (AQ) XXVIII 1, enero-junio 2007, pp. 101-142 ISSN 0211-3589 
LÁMINA III.--Inscripción donde se inserta el resumen-traducción de la $n .^{\circ} 4$

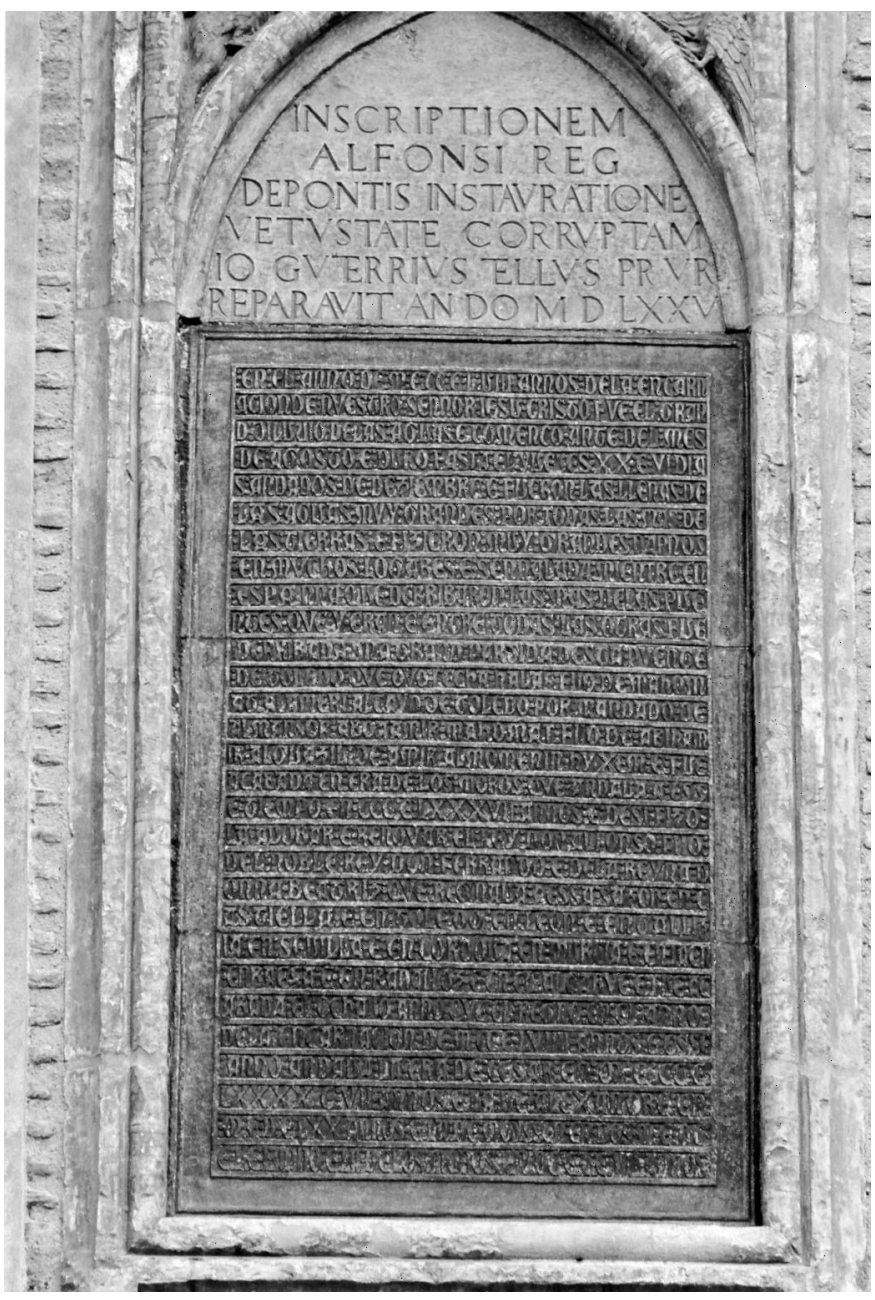

Al-Qanțara (AQ) XXVIII 1, enero-junio 2007, pp. 101-142 ISSN 0211-3589 
LÁMINA IV.--Inscripción n. ${ }^{\circ} 5$

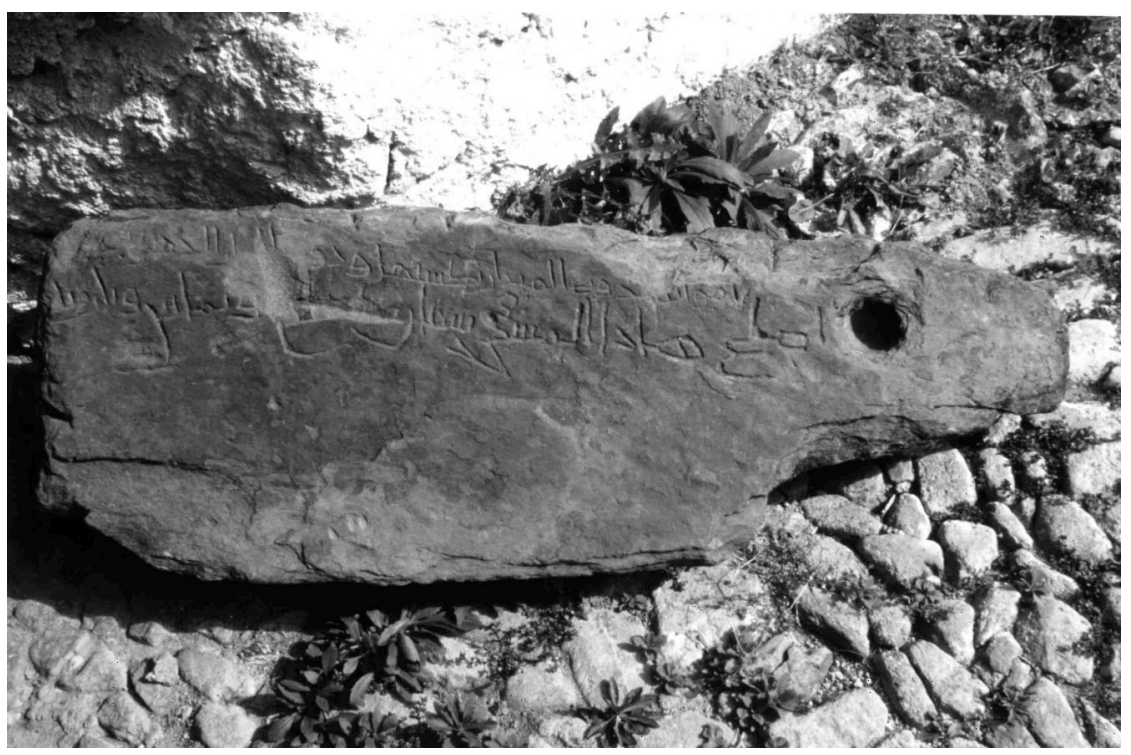

LÁMINA V.- Inscripción n. ${ }^{\circ} 6$

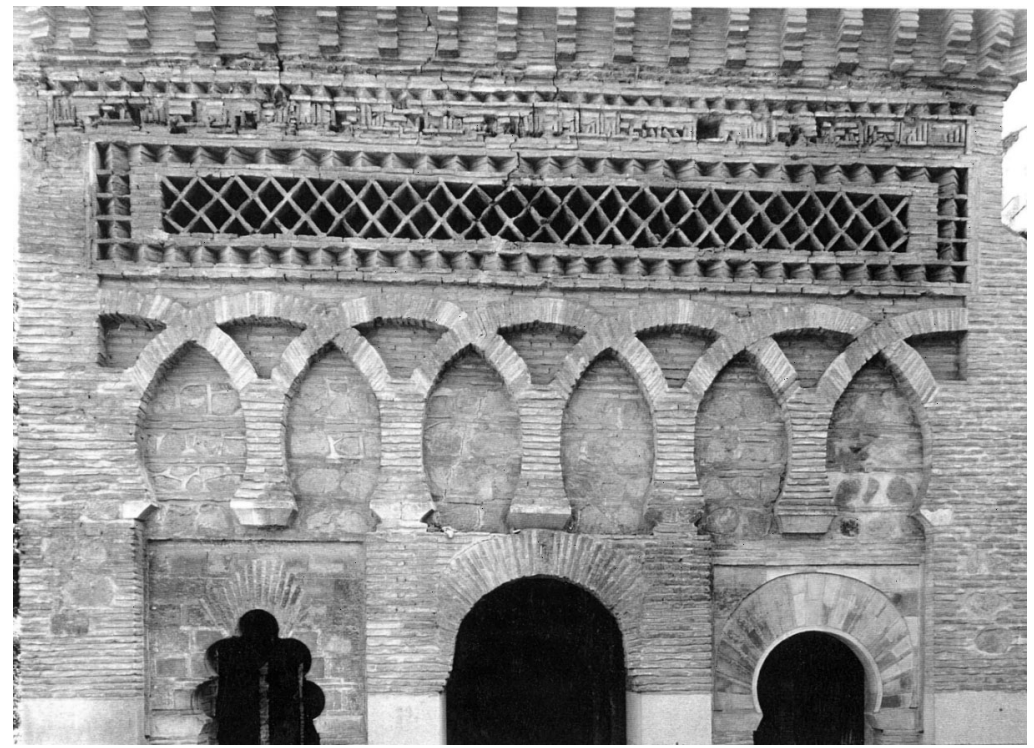

Al-Qanțara (AQ) XXVIII 1, enero-junio 2007, pp. 101-142 ISSN 0211-3589 
LÁMINA VI.--Inscripción n. ${ }^{0} 7$

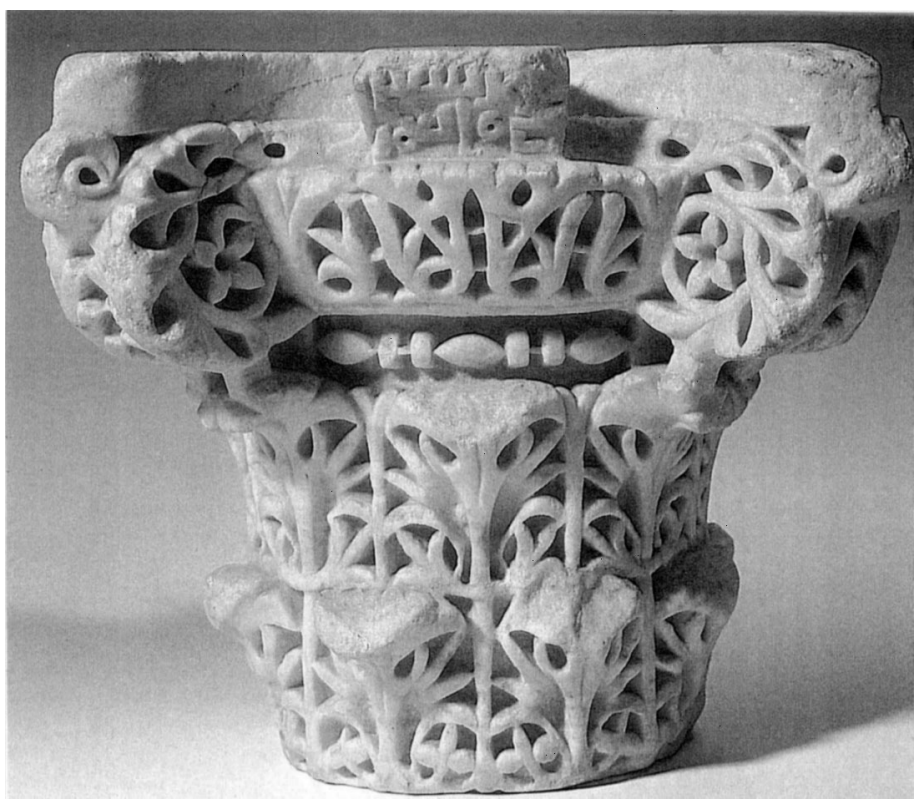

LÁmina VII.--Inscripción n. 8 ('Amal Bāšir y 'Amal Faraŷ)

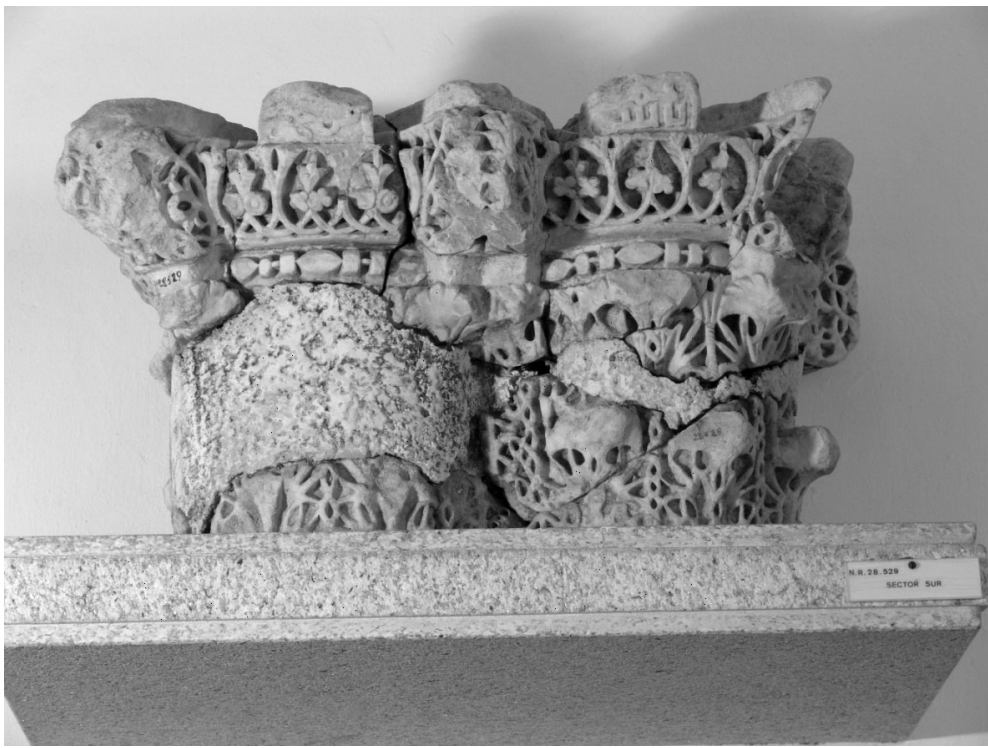

Al-Qanțara (AQ) XXVIII 1, enero-junio 2007, pp. 101-142 ISSN 0211-3589 
LÁminA VIII.--Inscripción n. 8 ('Amal Mubārak)

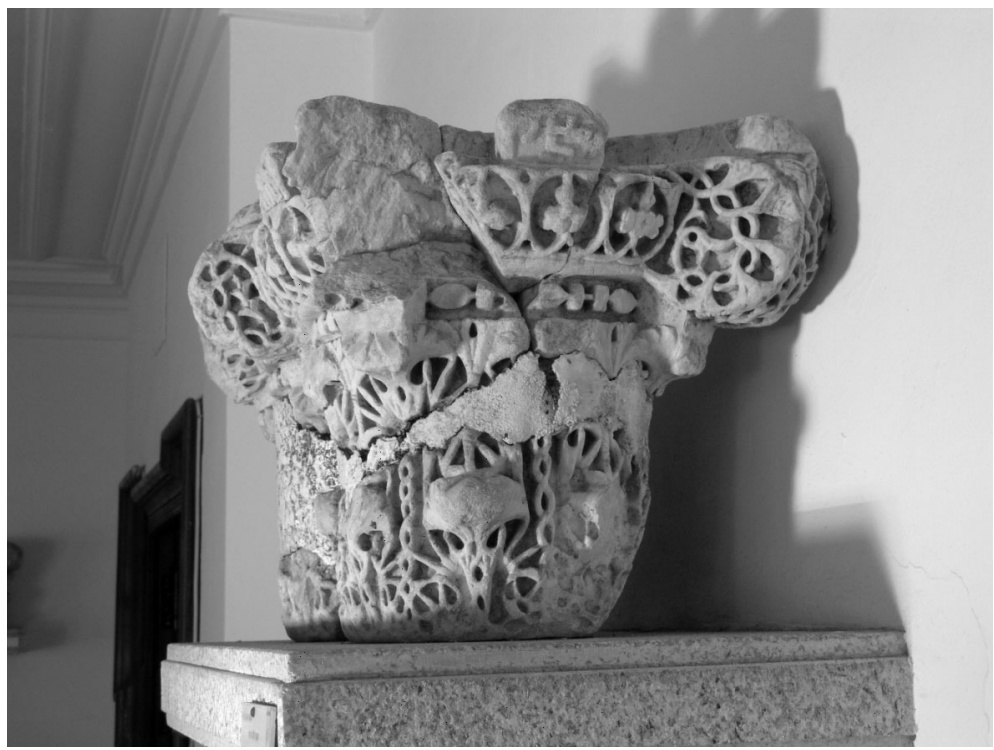

LÁMINA IX.--Inscripción n. ${ }^{\circ} 9$

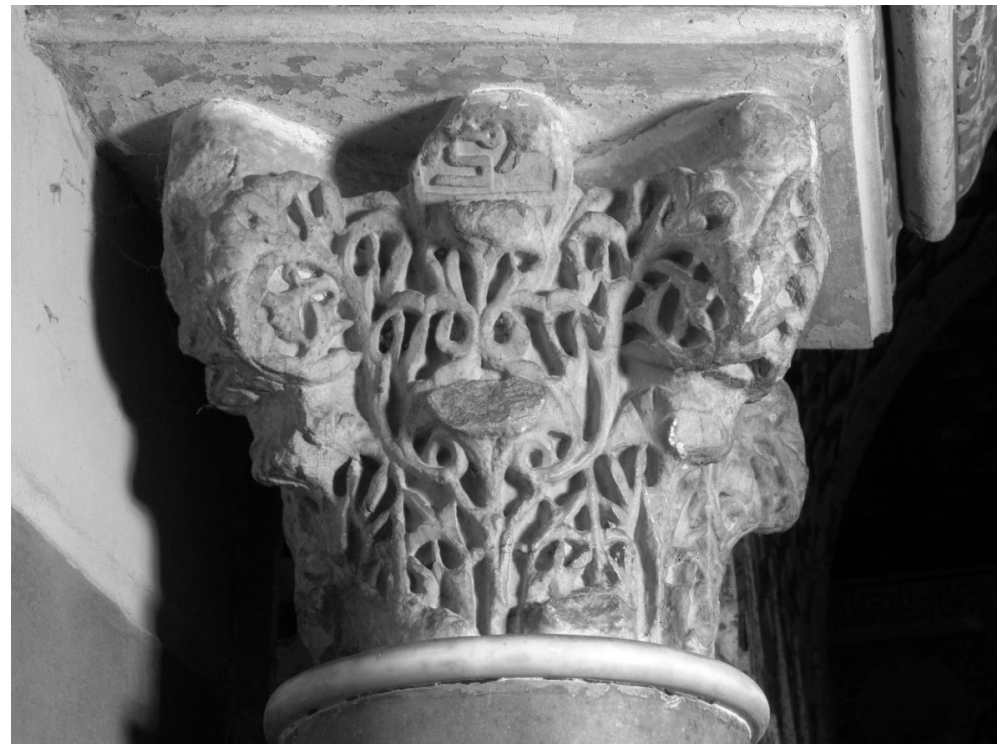

Al-Qanțara (AQ) XXVIII 1, enero-junio 2007, pp. 101-142 ISSN 0211-3589 
LÁMINA X.-Inscripción n. ${ }^{\circ} 10$

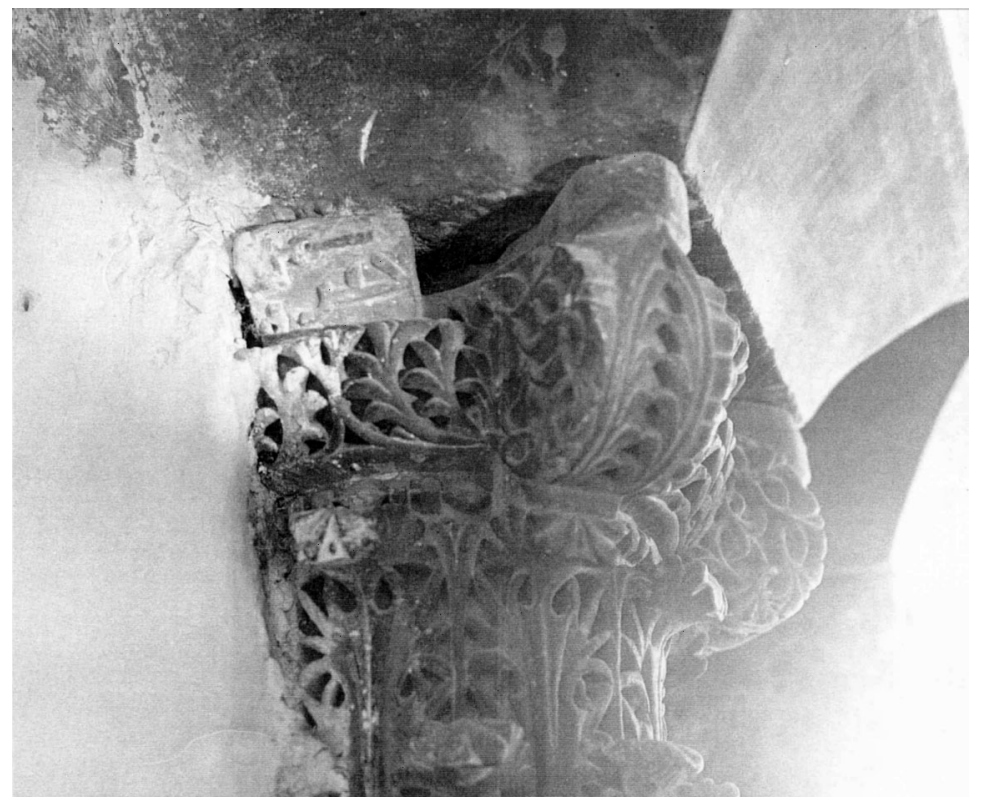

Al-Qanțara (AQ) XXVIII 1, enero-junio 2007, pp. 101-142 ISSN 0211-3589 
LÁMINA XI.-Inscripción n. ${ }^{\circ} 11$

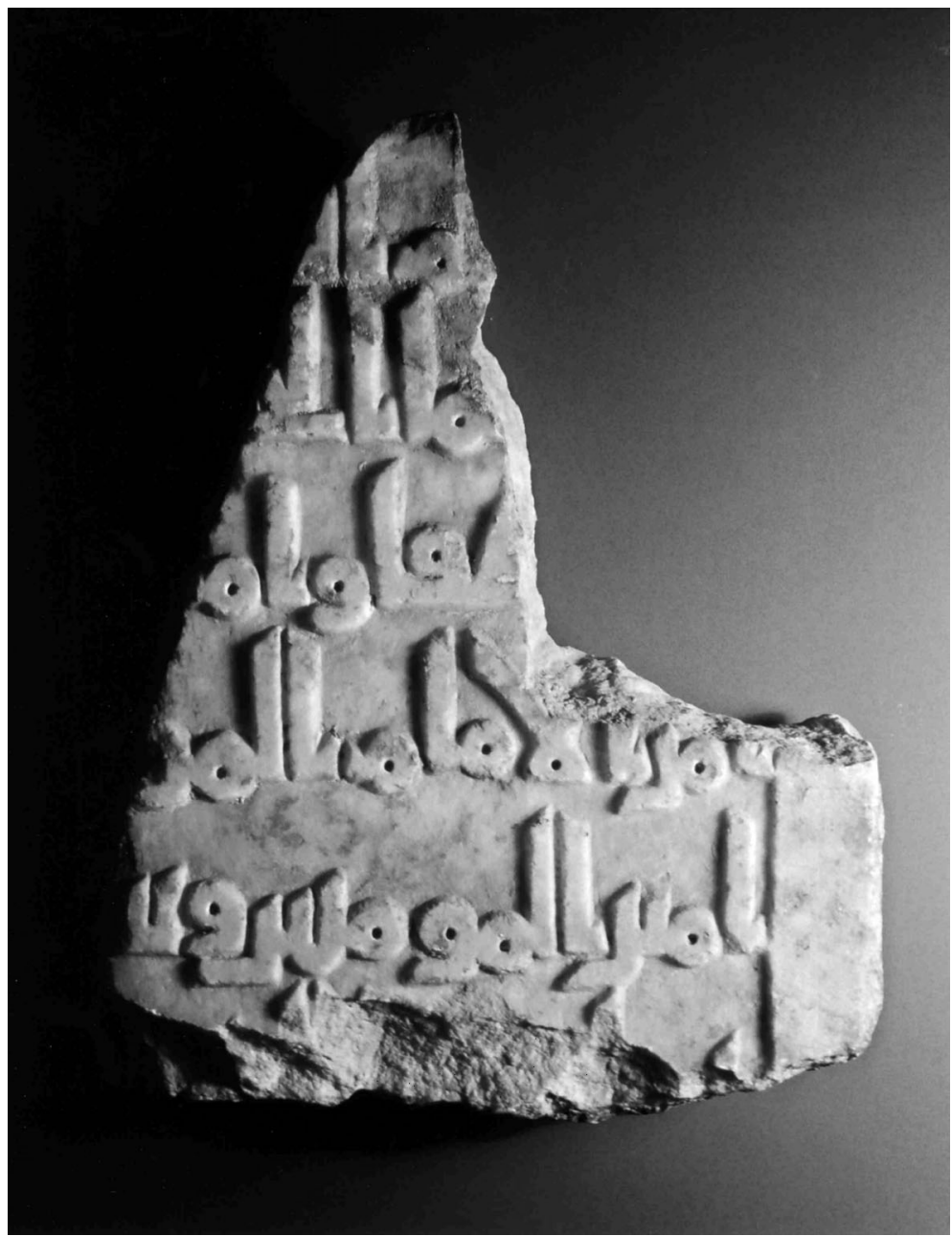

Al-Qanțara (AQ) XXVIII 1, enero-junio 2007, pp. 101-142 ISSN 0211-3589 
FiguRA 1.- Inscripción n. ${ }^{\circ} 1$

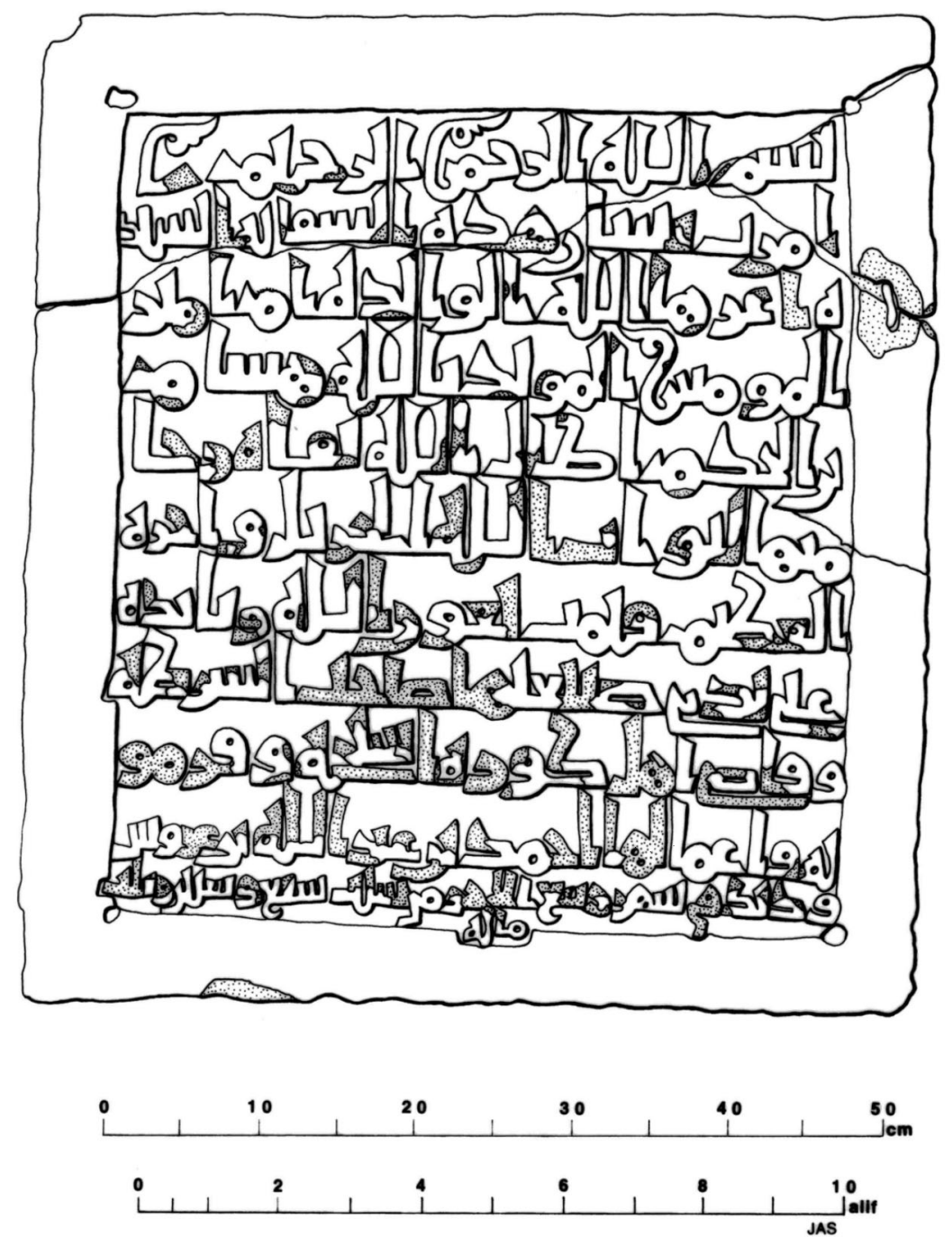


Figura 2.-Selección de signos lapidarios en columnas de la Mezquita Aljama de

Córdoba: a. Bāšir (fuste D13); b. Jayra (fuste E-27); c. Faraŷ (fuste H1); d.

Sa'āda (capitel F1); e. Mubārak (cimacio H4); f. Jalaf al-'Āmirī (fuste F31)
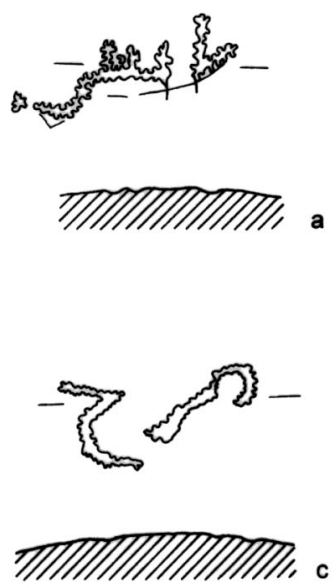
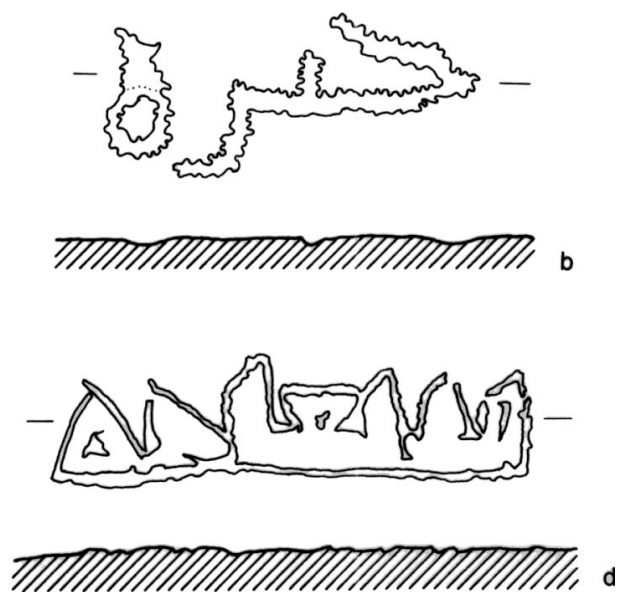

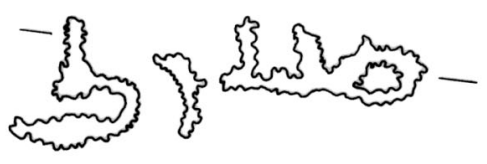

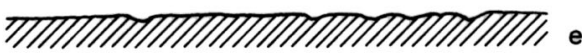
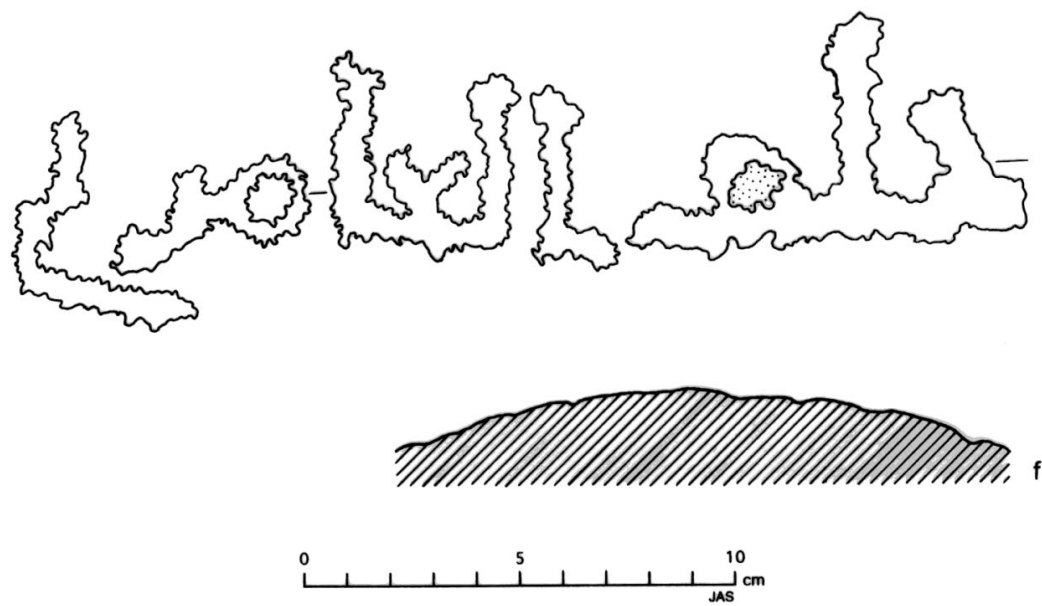

Al-Qanțara (AQ) XXVIII 1, enero-junio 2007, pp. 101-142 ISSN 0211-3589 
Figura 3.-Edición del texto de la inscripción donde se inserta el resumen-traducción de la $n .{ }^{\circ} 4$

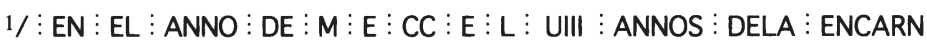

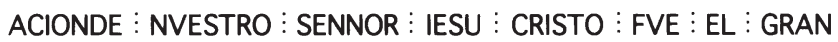

D : dILUUIO : DELAS : AGUAS : E : COMENCO : ANTE : DEL : MES

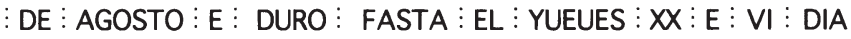
$S$ : ANDADOS : DE : DEZIEMBRE : E : FUERON : LAS : LLENAS : DE :LAS : AGUAS : MVY : GRANDES : POR : TODAS : LAS : MAS : DE : LAS : TIERRAS : E : FIZIERON : MUY : GRANDES : DANNOS : EN : MVChOS : LOGARES : E : SENNALADA : MIENTRE : EN : ESPANNA : QUE : DERRIBARON : LAS : MAS : DELAS : PUE NTES : QVE : Y : ERAN : E : ENTRE : TODAS : LAS : OTRAS : FUE $2 /$ : DERRIBADA : UNA ! GRAND : PARTIDA : DESTA ! PVENTE : DE : TOLEDO : QVE : OVO : FEChA : hALAF : FIIO : DE : MAhOM AT : ALAMERI : ALCAYD $:$ dE $\vdots$ TOLEDO : POR : MANDADO : DE ALMANÇOR : ABOAAMIR : MAhOMAT : FIIO : DE : ABIhAM IR $:$ ALGUAZIL $:$ DE $:$ AMIR $:$ ALMOMENIN $:$ hYXEM $:$ E $:$ FUE ACABADA : EN : ERA : DE : LOS : MOROS : QVE : ANDAUA A $\vdots$ ESS

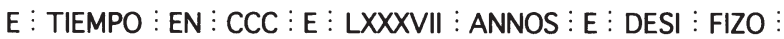
LA : ADOBAR : E : RENOVAR : EL : REY : DON : ALFONSO : FIIO : DEL : NOBLE : REY : DON : FERRANdO : E : DELA : REYNA :D ONNA : BEATRIZ : QUE : REGNAUA : AESSA : SAZON : EN : C ASTIELLA : E : EN : TOLEDO : EN : LEON : E : ENGALLIZ 3/IA : EN $:$ SEUILLA $:$ E $:$ EN $:$ CORDOUA $:$ EN $\vdots$ MURCIA $:$ E $\vdots$ EN $\vdots$ IAEN : ENBAEÇA : E : EN : BADALLOZ : E : EN $:$ EL $:$ ALGARVE $:$ E $\vdots$ FUE $:$ AC ABADA : EL : OChAUO : ANNO : QVE : EL : REGNO : EN : EL : ANNO : DELA : ENCARNACION : DE : M:CC:E : LVIIII $:$ ANNOS : E : ESSE

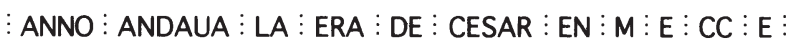
LXXXX : E : VII $\vdots$ ANNOS : E : LA $\vdots$ DE $\vdots$ ALEXANdRE $:$ EN :

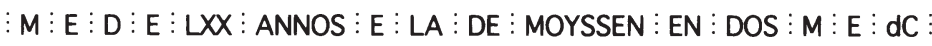
E $:$ L $:$ E $\vdots$ I $:$ ANNO $:$ E $:$ LA $:$ DELOS $:$ MOROS $:$ EN $:$ DC $:$ E $:$ L $:$ E $:$ VII $:$ ANNOS : 
FIgURA 4.-Inscripción n. ${ }^{\circ} 5$

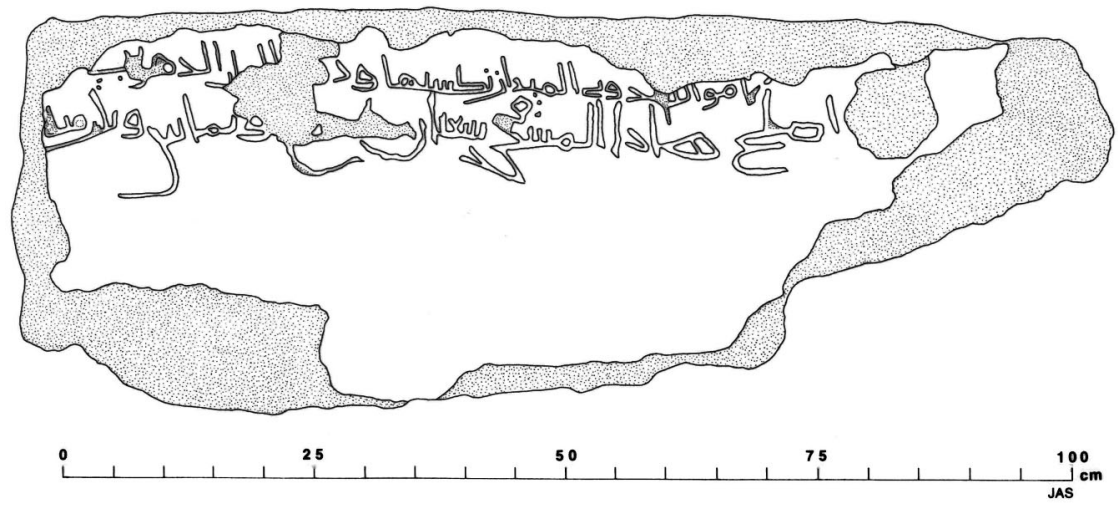

FigURA 5.--Inscripción n. ${ }^{\circ} 6$

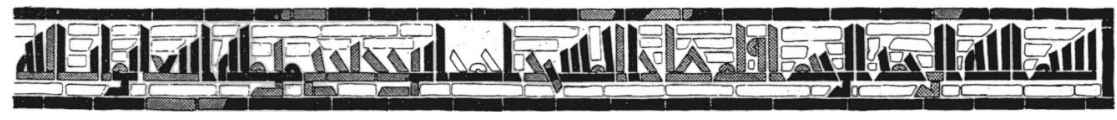

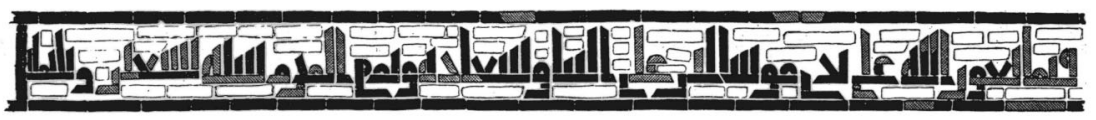

FiguRA 6.--Inscripción n. ${ }^{\circ} 7$

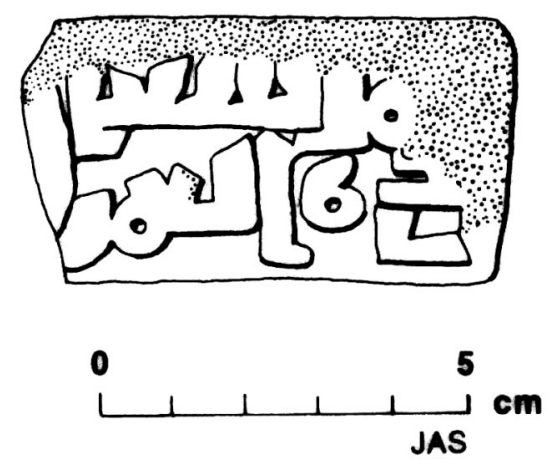

Al-Qanțara (AQ) XXVIII 1, enero-junio 2007, pp. 101-142 ISSN 0211-3589 
Figura 7.- Inscripción n. ' 8: a. 'Amal Bāšir;

b. 'Amal Farây; c. 'Amal Mubārak
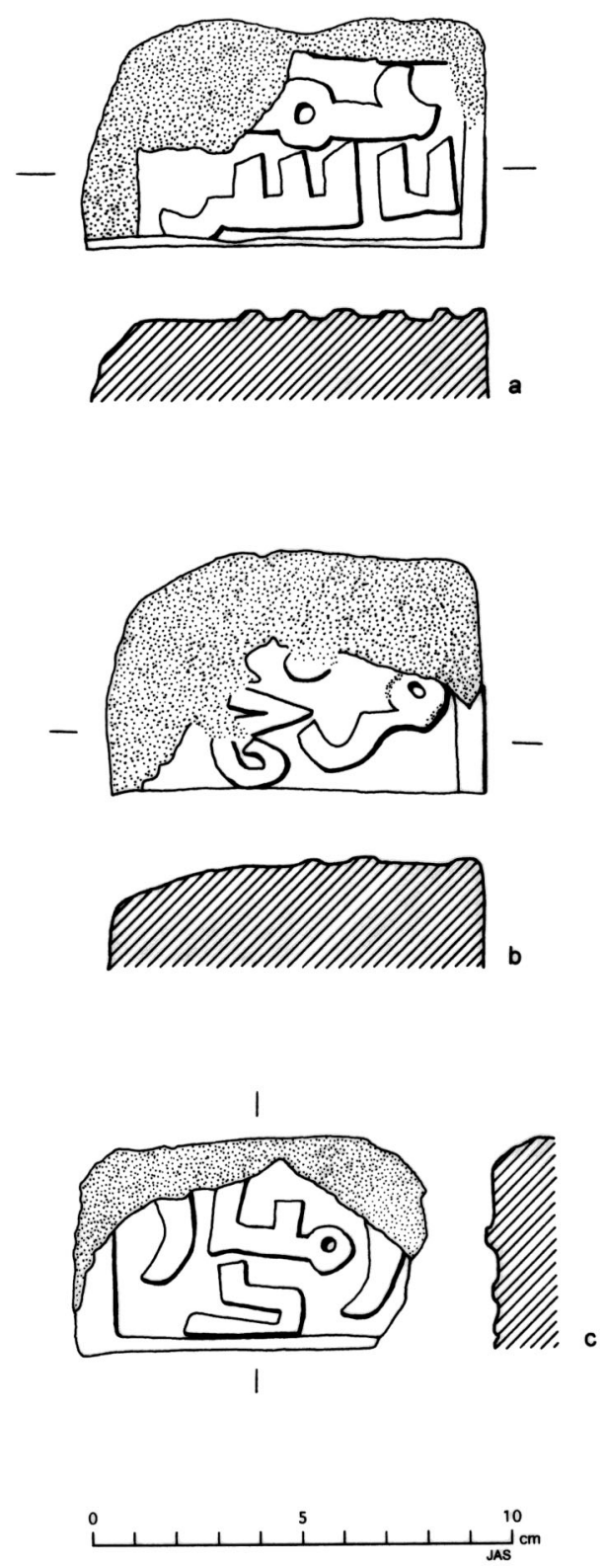

Al-Qanțara (AQ) XXVIII 1, enero-junio 2007, pp. 101-142 ISSN 0211-3589 
FiguRA 8.--Inscripción n. ${ }^{\circ} 9$
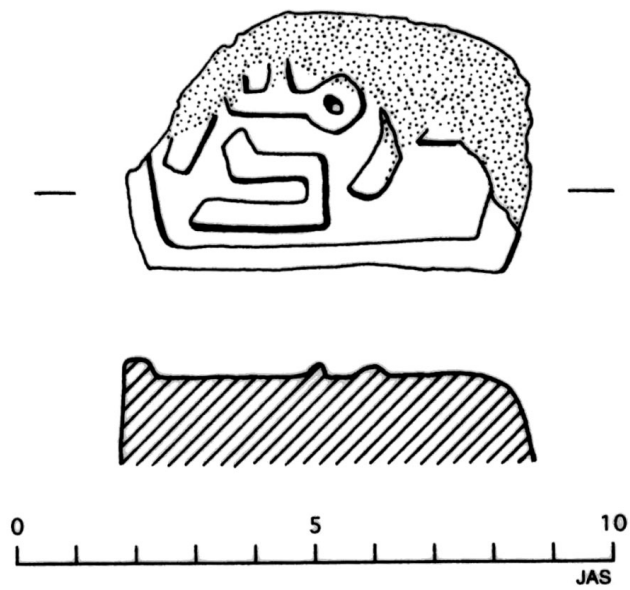

Figura 9.--Inscripción n. ${ }^{\circ} 11$.

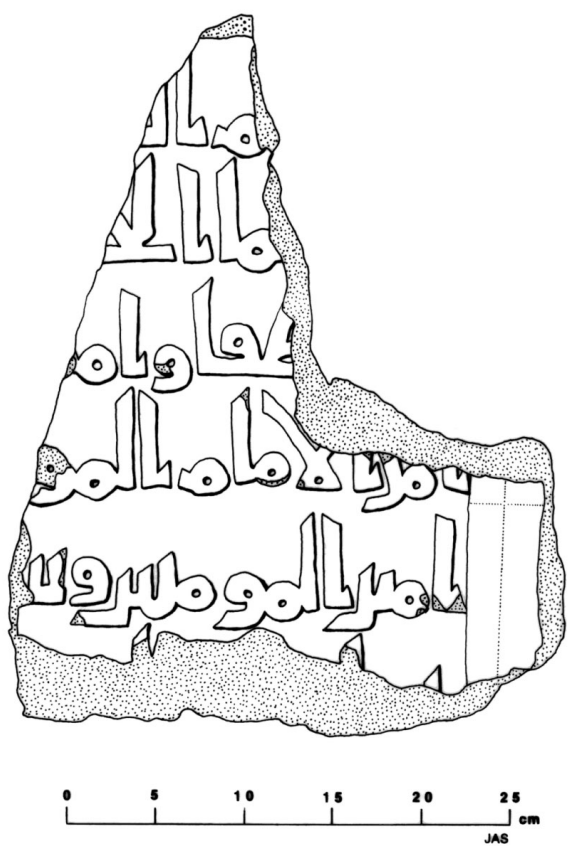

Recibido: $24 / 06 / 06$

Aceptado: 29/06/06

Al-Qanțara (AQ) XXVIII 1, enero-junio 2007, pp. 101-142 ISSN 0211-3589 